San Jose State University

SJSU ScholarWorks

Master's Theses

Master's Theses and Graduate Research

Spring 2012

\title{
Factors Influencing Athletic Training Students' Selection of Graduate Programs
}

Sonja E. Askew

San Jose State University

Follow this and additional works at: https://scholarworks.sjsu.edu/etd_theses

\section{Recommended Citation}

Askew, Sonja E., "Factors Influencing Athletic Training Students' Selection of Graduate Programs" (2012).

Master's Theses. 4119.

DOI: https://doi.org/10.31979/etd.4anq-kphn

https://scholarworks.sjsu.edu/etd_theses/4119

This Thesis is brought to you for free and open access by the Master's Theses and Graduate Research at SJSU ScholarWorks. It has been accepted for inclusion in Master's Theses by an authorized administrator of SJSU ScholarWorks. For more information, please contact scholarworks@sjsu.edu. 


\title{
FACTORS INFLUENCING ATHLETIC TRAINING STUDENTS' SELECTION OF GRADUATE PROGRAMS
}

\author{
A Thesis \\ Presented to \\ The Faculty of the Department of Kinesiology \\ San José State University \\ In Partial Fulfillment \\ of the Requirements for the Degree \\ Master of Arts
}

By

Sonja Askew, ATC

May 2012 
(c) 2012

Sonja Askew, ATC

ALL RIGHTS RESERVED 
The Designated Thesis Committee Approves the Thesis Titled

FACTORS INFLUENCING ATHLETIC TRAINING STUDENTS' SELECTION OF GRADUATE PROGRAMS

by

Sonja Askew, ATC

APPROVED FOR THE DEPARTMENT OF KINESIOLOGY

SAN JOSÉ STATE UNIVERSITY

May 2012

Dr. V. Gregory Payne Department of Kinesiology

Holly Brown Department of Kinesiology

Dr. KyungMo Han Department of Kinesiology 


\section{ABSTRACT}

\section{FACTORS INFLUENCING ATHLETIC TRAINING STUDENTS' SELECTION OF GRADUATE PROGRAMS by Sonja Askew, ATC}

There is no published research known to the author on factors that influence athletic training student enrollment in the graduate programs. An investigation was conducted to determine the factors influencing students' selection of graduate programs and their relationship to gender, age, and ethnicity. A web-based survey was developed with content adapted from the work of Johanson $(2004 ; 2007)$ and Wilcox, Weber, and Andrew (2005) to assess the factors. The survey was validated through a pilot study and by a panel of experts.

Newly accepted, currently enrolled, and graduate students in athletic training master's program were eligible to participate. Respondents $(n=410)$ ranked the importance of 41 factors and submitted open-ended responses to provide further insight on their choices. Data were analyzed using descriptive statistics, percentages, frequencies, and cross tabulations. Overall, the graduate assistantship factor was found to be the most influential. In addition, gender, age, and ethnicity were related to certain factors (e.g., geographic factors). Implications of this study include further research on the factors influencing 
athletic training student's selection of graduate programs and the need for better promotion of graduate programs. 


\section{ACKNOWLEDGEMENTS}

I would like to thank all the program directors, head athletic trainers, and especially the students, who participated in this study. I would also like to express my deepest gratitude to Dr. Payne, Holly Brown, and Dr. Han for their expertise, availability, and guidance along this journey. With their help, this challenging endeavor became an "achievable" work in which I am very proud. Many thanks to the Classes of 2011 and 2012 graduate athletic trainings students of San José State University for their participation in the pilot study.

I would like to give honor to God; for He blessed me with a wonderful graduate assistantship and an amazing family. A special thanks to my parents, Dennis and Bridget, for their unconditional love and endless support throughout this process. Also, I appreciated the encouraging words from my sister, Giovanna, while she was stationed in Guam. Most of all, I am thankful for my little brother and roommate, Dennis II, for all the times he cooked and cleaned so I could work on my thesis. Lastly, I would like to acknowledge Auntie Shelley for her constant support and the pride she took in my thesis. 


\section{TABLE OF CONTENTS}

Chapter 1 - Introduction...................................................................... 1

Statement of the Problem ........................................................................ 4

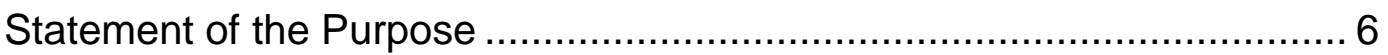

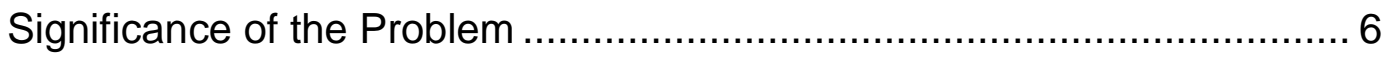

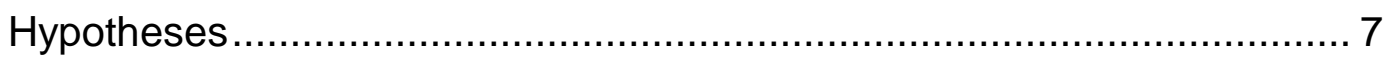

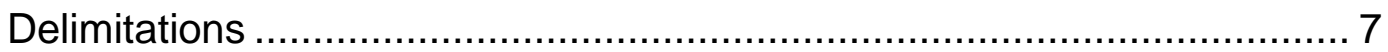

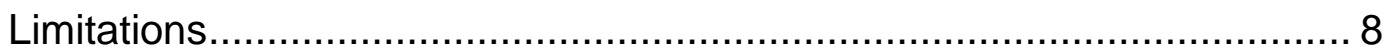

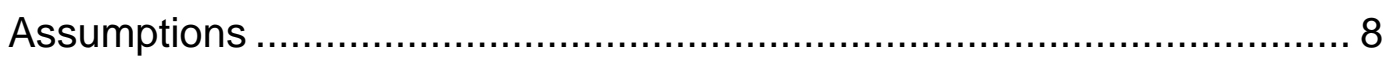

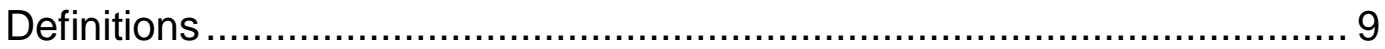

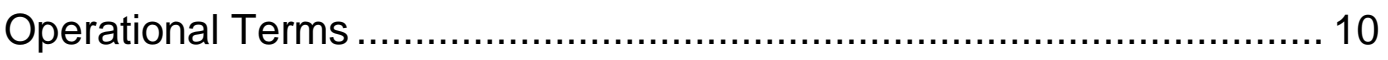

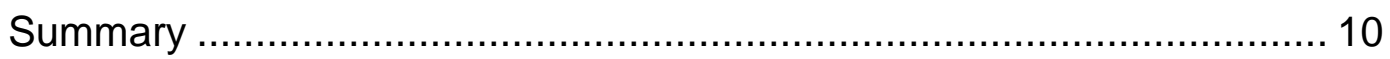

Chapter 2 - Review of Literature …........................................................ 12

Graduate Education Choices .......................................................... 13

Entry-level master's athletic training programs ........................... 13

Graduate athletic training education programs ........................... 14

Post-professional athletic training education programs.................. 14

Factors Influencing Physical Therapists............................................... 17

Factors Influencing Social Workers .................................................. 19

Factors Influencing Nurses ............................................................. 20

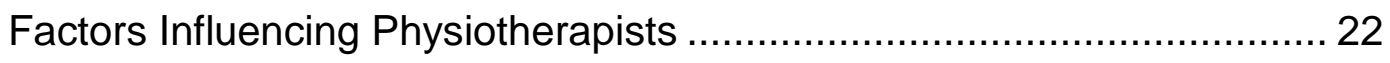

Factors Influencing Dental Hygienists ................................................ 24

Factors Influencing Marriage and Family Counselors ............................. 25

History of Athletic Training Education ................................................. 26

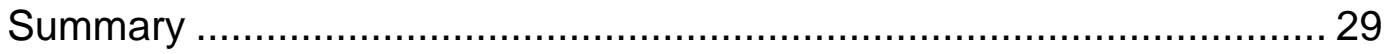

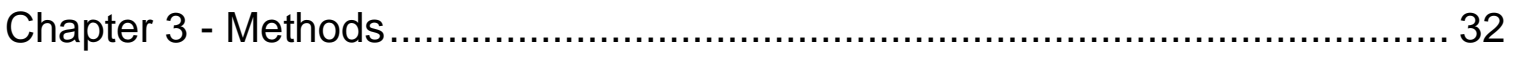

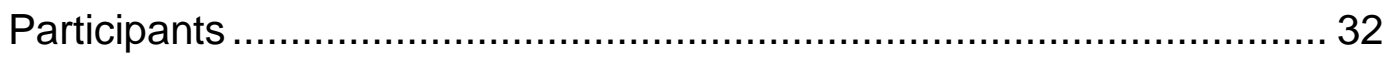

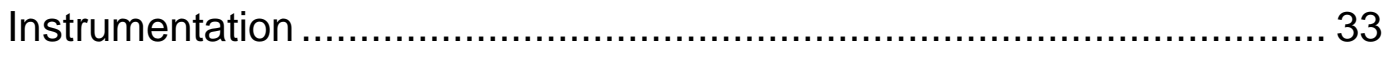




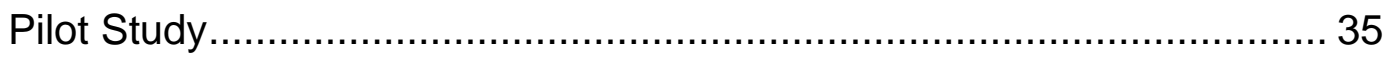

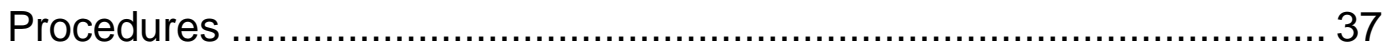

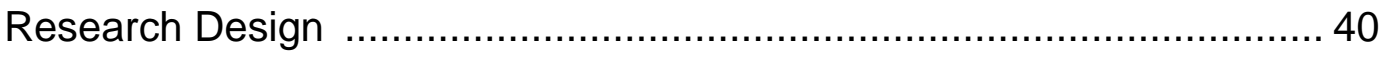

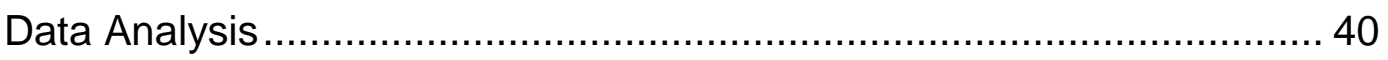

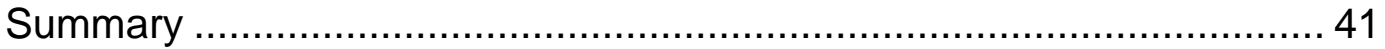

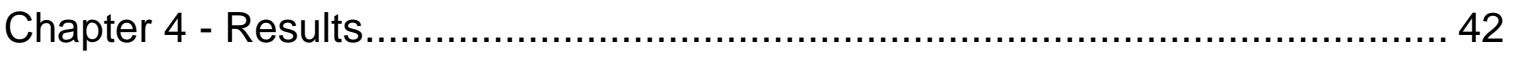

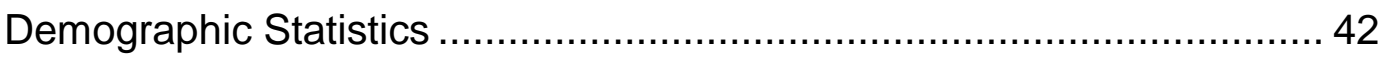

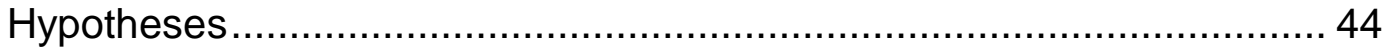

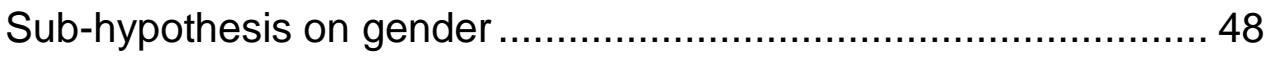

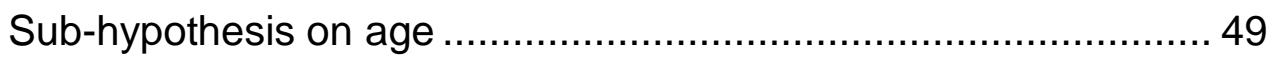

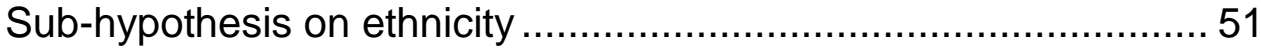

Analysis of Qualitative Responses.................................................... 54

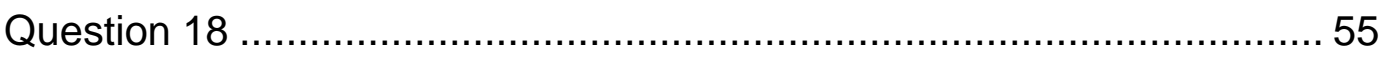

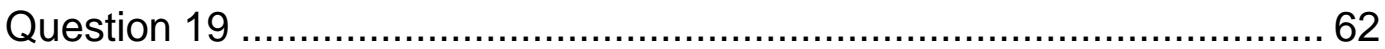

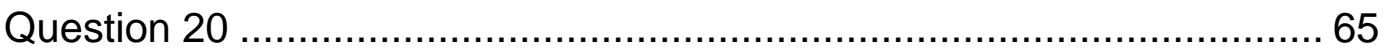

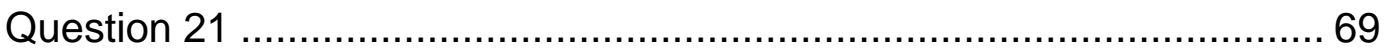

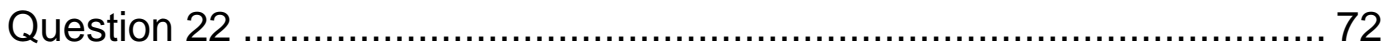

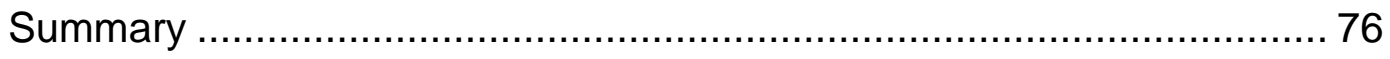

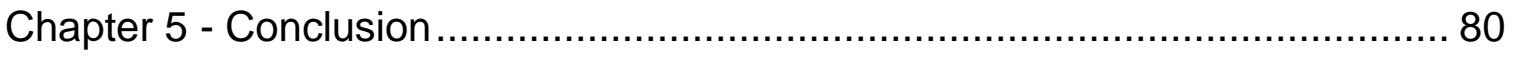

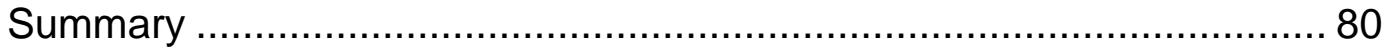

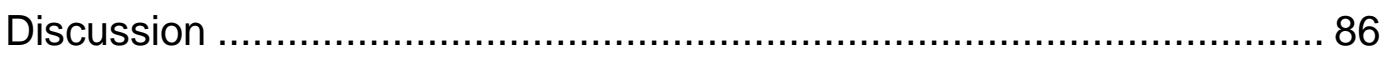

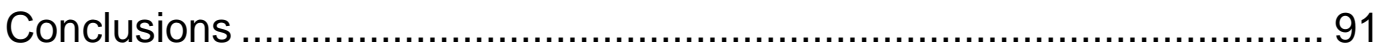

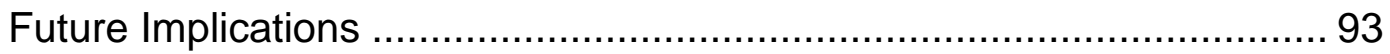

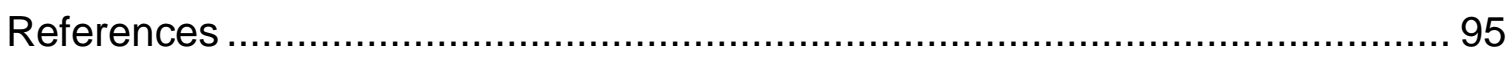

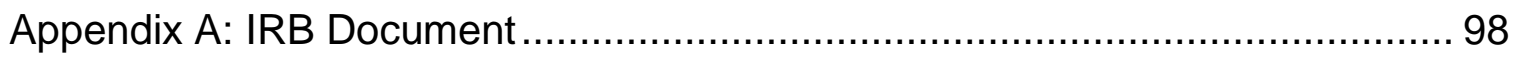

Appendix B: Letter to Program Directors/Head Athletic Trainers....................... 99

Appendix C: Reminder Letter Program Director/Head Athletic Trainers ........... 100

Appendix D: Letter to Graduate Students .................................................... 101

Appendix E: Reminder Letter to Graduate Students.................................... 102 
Appendix F: Sample Survey 


\section{List of Figures}

Figure 1. National Distribution of Post-Professional Athletic Training

Education Programs.................................................................. 3 


\section{List of Tables}

Table 1. Classification of Potential Factors of Influence by Categories ... 36

Table 2. Demographic Statistics of Participants..................................... 44

Table 3. Factors Ranked as Generally Very Important ............................ 47

Table 4. Differences Between Males and Females.................................. 49

Table 5. Differences Between Age Groups .......................................... 51

Table 6. Differences Between Ethnic Groups ........................................ 54 


\section{Chapter 1}

\section{Introduction}

In the discipline of athletic training, many students continue education beyond the baccalaureate degree. The National Athletic Trainers' Association (NATA) has reported that $70 \%$ of certified athletic trainers (BOCATCs) hold a master's or doctoral degree. According to the magazine, NATA News (2003), the Joint Review Committee on Athletic Training (JRC-AT) published statistics to track the progress of athletic training students following graduation from Professional (Undergraduate) Athletic Training Education Programs (ATEPs). Of 1,311 graduates in $2002,49 \%$ (636) went into the work force, while $51 \%(675)$ chose other routes (JRC-AT Tracks, 2003).

Among the $51 \%$ that chose other routes, $7 \%$ were unemployed, $35 \%$ continued their education, and 8\% did not report a status. Among the 469 students that pursued advanced degrees, 19\% students sought a master's degree in other health sciences, and $8 \%$ students sought a master's degree in non-health science fields. Only $8 \%$ students continued their education in pursuit of a master's degree in athletic training. One student sought a doctoral degree in athletic training. As several BOCATCs are continuing their education beyond the undergraduate degree, the majority of young professionals are choosing to continue their education in other fields. Eight percent of young professionals in the field possess advanced degrees in athletic training (JRC-AT Tracks, 2003). 
To understand how students select graduate programs, a look at master's programs available is warranted. Currently, there are 342 ATEPs accredited by the Commission on Accreditation of Athletic Training Education (CAATE) and 15 Post-Professional Athletic Training Education Programs (PATEPs) accredited by the NATA (Winterstein, 2009). With this disparity between the number of accredited undergraduate and graduate programs, maintaining the number of students in the profession is challenging. Winterstein (2009) notes, "Many students choose to pursue graduate study in an area outside of athletic training" (p.55).

Furthermore, the location of the 15 PATEPs is noteworthy. Eleven of the 15 accredited graduate programs are located east of the Mississippi River (see Figure 1. on the next page.) In turn, this leaves only three graduate programs on the west coast for hundreds of students. For students living west of the Mississippi River and hoping to stay close to home, selection of an accredited graduate program is challenging with options limited to PATEPs in Oregon, Arizona and Hawaii.

Other reasons for students continuing their education in other fields include but are not limited to the assumption that graduate courses will be the same as undergraduate courses, the need for something else to fall back on education-wise, the lack of conveniently located PATEPs, and lack of awareness of options (Ingersoll \& Gieck, 2005). It is common for one to obtain an advanced degree in another discipline. Ingersoll and Gieck (2003) insist there is nothing 
wrong with pursing an advanced degree in another area if it meets that individual's professional needs.

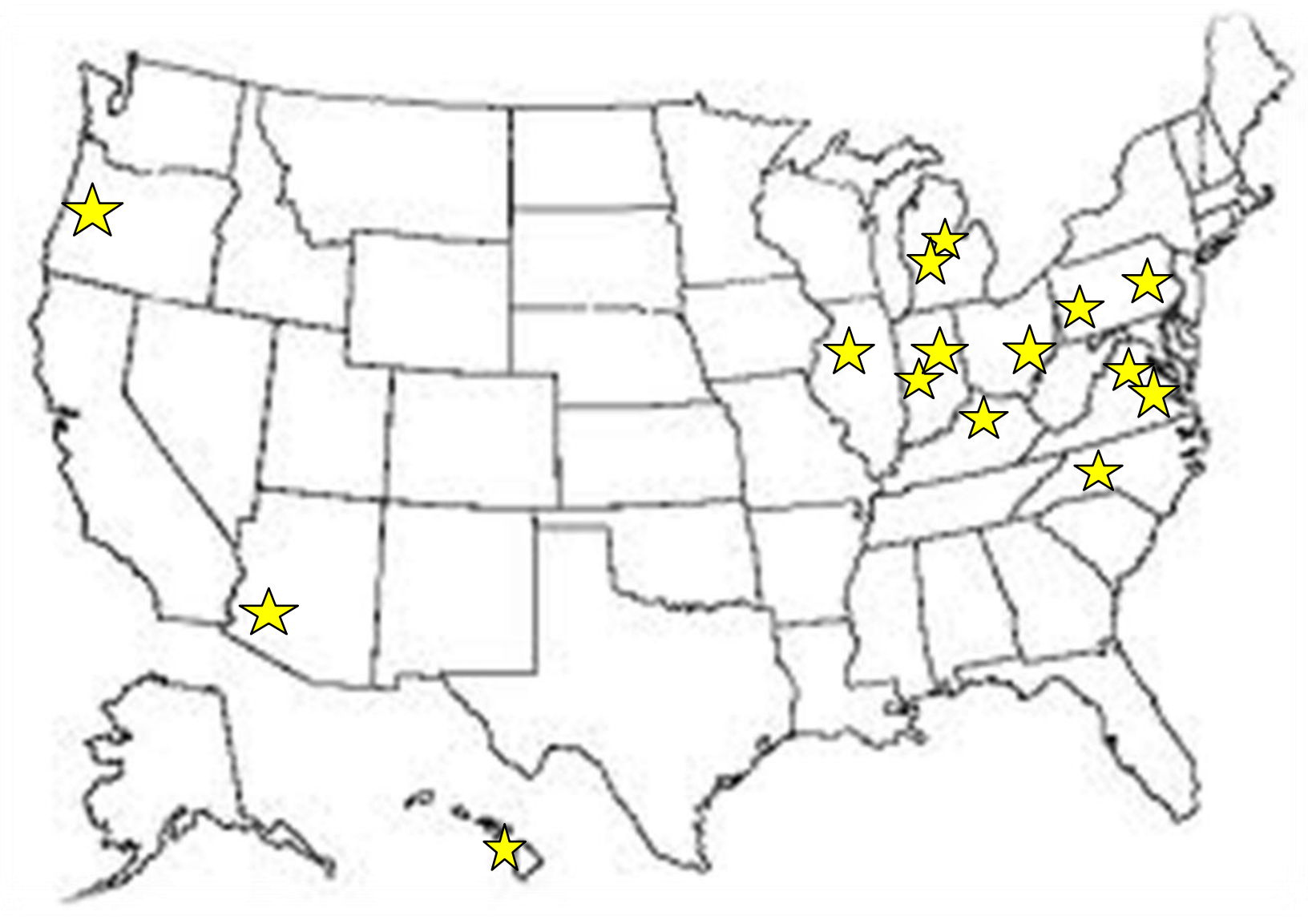

Figure 1. National Distribution of Post-Professional Athletic Training Education Programs

The variables influencing the students' selection of a graduate program are a critical area of inquiry to many educators in athletic training, though no research to our knowledge has been conducted. Graduate education in athletic training is understudied, and more research is needed to understand the decision-making process of students. Therefore, this study sought to explore the 
factors that influence students and determine the most influential factors in their choice of graduate programs. The continued development of athletic training education has led to NATA-accredited master's programs; nevertheless, many students still choose to pursue a master's degree in another field.

\section{Statement of the Problem}

Athletic training students are often advised to pursue an advanced degree in another field of study (Ingersoll \& Gieck, 2005). When the Board of Certification was established as the credentialing body for the National Athletic Trainers' Association (NATA), it was mandated that athletic trainers attain certification by: (1) completing an internship in athletic training, or (2) continuing their education in pursuit of a master's degree in physical therapy (Perrin, 2007). In the 1950s, this could be attributed to William E. Newell, the father of modern day athletic training and the first athletic trainer concurrently credentialed as a physical therapist (Delforge \& Behnke, 1999). When Newell introduced the first athletic training curriculum model in 1959, the courses were recommended by the American Physical Therapy Association for athletic trainers to meet the prerequisites to gain acceptance into physical therapy schools (Delforge \& Behnke, 1999). In turn, this set the tone for athletic trainers pursuing study in other fields.

When athletic training was first introduced, it was thought to be such a diverse profession that many BOCATCs needed additional training in other fields of study to be viewed as marketable. For instance, BOCATCs working in 
secondary schools would obtain teaching credentials as they were expected to be able to teach. Historically, the role of an athletic trainer was to function as a teacher-trainer (Delforge \& Behnke, 1999). Consequently, in preparation to be an athletic trainer, the first education model included curriculum to become health and physical educators (Delforge \& Behnke, 1999).

First generation athletic trainers (those born in the period following WWII or possessing a degree in Physical Education) may be more likely to advise young professionals to obtain their master's degree in something else because that is what they did. In turn, this has lead to many students pursuing advanced degrees in health sciences (e.g., physical therapy, physiotherapy, physician's assistant) or non-health sciences (e.g., business administration, leadership and management, sport management). However, there are other options available for athletic trainers to continue their education specifically in athletic training, similar to other health care professionals (e.g., dentists, physical therapists, nurses) who stay in their field to continue their education.

Consequently, in the future, few athletic trainers may hold master's degrees in athletic training, and even fewer will hold degrees from NATAaccredited programs. Similarly, the number of accredited graduate programs could decrease. While first generation athletic trainers are unaware they are promoting advanced degrees in other disciplines over athletic training, this could be construed as denouncing the profession of athletic training. 
First generation athletic trainers may be conveying a subtle message that a master's degree in anything will suffice. Thus, instead of encouraging students to be the best practitioners, capitalize on their expertise, and contribute to the body of literature in athletic training, athletic trainers seek advanced education in the other fields. Another disadvantage of this message is that it does not promote graduate education at PATEPs which have worked hard to launch programs, harder to recruit students, and even harder to maintain the status of accreditation.

\section{Statement of the Purpose}

The purpose of this study was to explore the factors that influence athletic training students' selection of graduate programs and determine the most influential factors. This includes examining the effects of gender, age, and ethnicity.

\section{Significance of the Problem}

Although there has been research conducted on various aspects of graduate education in athletic training (Henry, Van Lunen, Udermann, \& Oñate, 2009; Ingersoll \& Gieck, 2003; Ingersoll \& Gieck, 2005; JRC-AT Tracks, 2003; Keskula, Sammarone, \& Perrin, 1995; Rasmussen-Wilbert, 2007; Seegmiller, 2006), an exhaustive review of literature revealed no research to determine the factors that influence athletic training students' selection of graduate programs. As previously stated, there are currently 15 PATEPs and 342 ATEPs in the nation (www.caate.net). The ratio of ATEPs to PATEPs is approximately 22:1; 
the number of ATEPs to all graduate athletic training education programs (GATEPs) is uncertain.

Clearly, the existing 15 NATA-accredited PATEPs cannot accommodate all the students graduating from 342 CAATE-accredited ATEPs across the nation. Nevertheless, giving more students the option of attending these programs to better the profession and retain students is critical. The profession must address this concern from within (1) to increase the number of accredited graduate programs, (2) to recruit more students to pursue advanced degrees in the profession rather than something else, and (3) to align the standards of the profession with those of other health care professions to improve athletic training education.

\section{Hypotheses}

In addition to the hypothesis that there will be no single factor that stands out as the most influential, there will be minimal effects of gender, age, and ethnicity on the factors influencing students' selection of graduate programs.

\section{Delimitations}

The research was limited to:

1. Newly accepted students, currently enrolled students, and recent athletic training graduates of any master's program of study;

2. The use of a computer generated survey which each participant completes once. 


\section{Limitations}

The following limitations were acknowledged as they may have had an effect on the outcome of the research:

1. Willingness of participants to complete the survey;

2. Motivation of participants to respond completely and honestly;

3. Contact information listed on college websites that may have excluded email addresses;

4. Willingness of program directors and head athletic trainers to distribute the survey to students;

5. Indeterminate population of the graduate athletic training students;

6. Possibility that the responses returned may not accurately represent all graduate athletic training students;

7. Potential bias of the principal investigator;

8. Inability to determine a response rate for surveys forwarded by program directors and head athletic trainers.

\section{Assumptions}

The following assumptions were made during the conduct of this research:

1. Program directors and head athletic trainers voluntarily and willingly distributed the survey to students;

2. The survey directions were clear and understood;

3. All students completing the survey were fluent in English; 
4. Contact information found on the institution's athletics or sports medicine website was current and accurate;

5. Once graduate athletic training students received the survey link through email, and clicked the hyperlink, it functioned accurately.

\section{Definitions}

Certified Athletic Trainers (BOCATCs). A "specialist in athletic health care" with a BA/BS degree from a CAATE-accredited program and has passed the Board of Certification Exam (Prentice, 2006, p. 2).

Commission on Accreditation of Athletic Training Education (CAATE). A group formed "to provide premier accreditation services to institutions that offer Athletic Training programs, verify that all CAATE-accredited programs meet the standards for professional education, and support continuous improvement in the quality of athletic training education" (http://www.caate.net/imis15/caate/).

National Athletic Trainers' Association (NATA). The governing body and "professional membership association for BOCATCs and others who support the profession of athletic training" (http://www.nata.org/aboutNATA).

Professional Athletic Training Education Program (ATEP). CAATE-accredited "programs for students seeking to become certified athletic trainers," formerly known as undergraduate programs (http://www.nata.org/ProfessionalEduPrgms). Entry-Level Master's Athletic Training Programs (ELMs). CAATE-accredited "programs for students seeking to become certified athletic trainers." Only these 
programs can confer master's degrees in athletic training (http://www.nata.org/ProfessionalEduPrgms).

Post-Professional Athletic Training Educational Program. "To expand the depth and breadth of the applied, experiential, and propositional knowledge and skills of entry-level certified athletic trainers, expand the athletic training body of knowledge, and to disseminate new knowledge in the discipline" (National Athletic Trainers' Association, Standards and Guidelines, 2002).

\section{Operational Terms}

First Generation Athletic Trainers. Athletic trainers born after World War II and possessing bachelor/master's degree in physical education for athletic training. PATEP. An abbreviation for a Post-Professional Athletic Training Education Program; also utilized in previous research by Henry, Van Lunen, Udermann \& Oñate (2009).

Graduate Athletic Training Education Program (GATEP). Operationally defined as a master's athletic training education program that is not NATA-accredited or CAATE-accredited, but confer a master's degrees in athletic training.

\section{Summary}

Athletic training is a health care profession requiring a bachelor's degree, yet more than $70 \%$ of athletic trainers have advanced degrees (http://www.nata.org/athletic-training). Unlike other well-established health care professions, athletic training is still fairly new to the public and was only recently acknowledged by the American Medical Association as an allied health care 
profession, specifically categorized as Physical Rehabilitation and Medicine (“AMA endorse," 1990). To develop athletic training as a legitimate profession, the educational programs and standards of practice were modeled after those of other health care professions. Today, many students are motivated to purse a master's degree, yet few actually continue their education in athletic training (Ingersoll \& Gieck, 2005; Winterstein, 2009). Overall, the factors influencing athletic training students to select one graduate program over another are not well understood. Therefore, this study sought to explore the factors that influence students' selection of graduate programs and to further investigate the effects of gender, age, and ethnicity. 


\section{Chapter 2}

\section{Review of Literature}

The purpose of this literature review was to gain insight into the critical areas that may influence students' selection of graduate programs. All research for the literature review was conducted through San José State University's King Library and Database Resources for Kinesiology. The primary search engines utilized were CINAHL, ScienceDirect, Web of Science, SPORTDiscus, ProQuest Dissertations and Theses, and ERIC via Esbco. Some of the key terms used to search for articles included education, program selection, student choice, graduate studies, student influences, college influences, master's level study, and many more.

Only a few articles were found pertaining to graduate students in athletic training let alone what influenced these students to pursue graduate education. Instead, the same search was performed in other health care professions in an attempt to reveal what, if any, comparable studies have been conducted in this area. Within the fields of dentistry (Kanji, Sunell, Boschma, \& Craig, 2010), nursing (Kippenbrock, 1990; Meadus, 2000), physiotherapy (Glover, Bulley, \& Howden, 2008), physical therapy (Johanson, 2004; Johanson, 2007; Wilcox et al., 2005), social work (Kindle \& Colby, 2008), and counseling (Hertlein \& Lambert-Shute, 2007), previous research examined what motivated students and why they chose graduate programs. These research articles were also retained to be utilized as a guide for methodology. 
The purpose of this study was to investigate the factors that influence athletic training students' selection of graduate programs. It was also designed to distinguish relationships among the factors that may influence varying age groups, ethnic groups, and genders. This chapter contains a review of pertinent and current literature as it relates to the problem of significance. It is divided into eight sections: (1) Graduate Education Choices: Entry-Level Master's Athletic Training Education Programs, Graduate Athletic Training Education Programs and Post-Professional Athletic Training Education Programs, (2) Factors Influencing Physical Therapists, (3) Factors Influencing Social Workers, (4) Factors Influencing Nurses, (5) Factors Influencing Physiotherapists, (6) Factors Influencing Dental Hygienists, (7) Factors Influencing Marriage and Family Counselors, and (8) History of Athletic Training Education. Following the review of literature, a brief summary is presented.

\section{Graduate Education Choices}

\section{Entry-level master's athletic training education programs.}

Undergraduate students approaching graduation and seeking to continue their education are faced with an array of graduate programs to choose from. Among those graduate programs, Entry-Level Master's Athletic Training Education Programs (ELMs) are available. These fairly new programs are CAATEaccredited and confer a Master's Degree in Athletic Training. Similar to ATEPs, students attending these programs become eligible to sit for the Board of 
Certification Exam after graduating. In 1996, Bridgewater State University in Pennsylvania became the first ELM, followed by Plymouth State University in New Hampshire (www.caate.net). Today, there are 24 ELMs nationwide (www.caate.net). Rasmussen-Wilbert (2007) investigated barriers to developing these programs and found there are not enough athletic trainers possessing doctoral degrees to manage the programs.

Graduate athletic training education programs. Students can also consider attending a program that is unaccredited. Graduate Athletic Training Education Programs (GATEPs) are not CAATE-accredited like ELMs, nor are they NATA-accredited like PATEPs. However, several programs like these exist across the nation. GATEPs may confer a Master's in Athletic Training or a master's degree with concentration or emphasis in Athletic Training. Winterstein (2009) claims graduate education options vary and that students are left confused by the many options. He adds that while students may decide to study in a similar field, graduate and professional goals vary from one program to the next. With these options (e.g. PATEPs, ELMs and GATEPs) and the option of pursuing graduate study outside athletic training, retaining students in the field has been challenging (Winterstein, 2009).

Post-professional athletic training education programs. With only 15 PATEPs in the nation, these NATA-accredited programs are sought by undergraduate students seeking to capitalize on their skills. Program directors 
often receive five times the number of applicants than they have seats for (Keskula et al., 1995). The following is a list of current PATEPs:

$\begin{array}{ll}\text { A.T. Still University } & \text { Oregon State } \\ \text { California University of Pennsylvania } & \text { Temple University } \\ \text { Illinois State University } & \text { University Arizona } \\ \text { Indiana State University } & \text { University of Hawaii at Manoa } \\ \text { Indiana University } & \text { University of Kentucky } \\ \text { Michigan State } & \text { Univ. North Carolina at Chapel Hill } \\ \text { Old Dominion University } & \text { Western Michigan State } \\ \text { Ohio University } & \end{array}$

Additional research pertaining to the students attending PATEPs examined the curriculum satisfaction (Henry et al., 2009), perceptions of quality (Seegmiller, 2006), and benefits of attending a PATEPs (Ingersoll \& Gieck, 2003; "Why Pursue," 2011).

Athletic training programs that are accredited exhibit quality educational programs. Seegmiller (2006) found curriculum, adequate faculty and administrative staff, research, and clinical experience, were the greatest characteristics of program quality. Despite the stereotype that a Bachelor's in Athletic Training is good enough for athletic trainers and incurring a Master's in Athletic Training was repeating one's undergraduate education, another study dismissed this perception. Henry et al. (2009) found that graduates of PATEPs were generally satisfied with their education and especially the curriculum. Henry 
et al. (2009) also stated that students who took more time to graduate seemed to be less satisfied than students who graduated on time. With few published studies concerning graduate students at PATEPs, this continues to be an area of growing interest in the profession.

\section{Factors Influencing Physical Therapists}

In the field of physical therapy, researchers have examined the influences in selecting certain graduate programs (Johanson, 2004; Johanson, 2007; Wilcox et al., 2005). Johanson (2004) determined that the factors that influence Master of Physical Therapy (MPT) students differed from those that influence Doctor of Physical Therapy (DPT) students. After completing two pilot studies, the survey was mailed to 34 programs directors. Then, the programs directors distributed the survey to students. Altogether, 919 surveys were returned resulting in a response rate of $78.4 \%$. To calculate the differences between MTP and DPT students, Johanson (2004) used independent t-tests, chi-square, and logistic regression analysis. Descriptive statistics were used to report gender, age, and ethnicity (Johanson, 2004).

The mother's education contributed significantly to predicting the student's level of education. The higher the mother's education, the more likely the students were to be enrolled in a DPT program. DPT students were twice as likely to be females and enrolled in private institutions. Other significant differences were present in the influence of a Master of Physical Therapy degree 
being conferred as opposed to a Doctorate of Physical Therapy degree being conferred. While $53.3 \%$ of DPTs felt the degree was a deciding factor, only 11.2\% MPTs agreed. MPT students found class size, matriculation date, marketability of degree, and length of the program to be more important. However, DPT students focused more on curriculum, availability of DPT degree, faculty reputation, and degree conferred (Johanson, 2004).

The following year, Wilcox and associates (2005) investigated the factors influencing minority students' choice of physical therapy programs. Similar to Johanson (2004), the survey was given to program chairs to be distributed to students. Although some students omitted answers, surveys with less than five missing responses were still retained. To analyze the data from Likert-scaled responses, numerical values were assigned. The Kruskall-Wallis analysis indicated significant statistical differences between minority and non-minority students. The minority students were more influenced by cost, ethnic/culture and gender issues, and faculty at physical therapy programs than were non-minority students (Wilcox et al., 2005).

In 2007, Johanson published another research article. This one pertained to the differences between various ethnic groups and genders as students selected a physical therapy program. As the profession of physical therapy is predominately Caucasian/White female clinicians, this study targeted men and minorities to increase diversity (Johanson, 2007). Women were found to place 
more importance on cost, location, financial aid, and campus environment, while men found reputation of the faculty more important. Minority clinicians considered the availability of financial aid, prerequisites, and their interaction with the student population to be deciding factors, but non-minority clinicians cared more about the reputation of the faculty (Johanson, 2007). Overall, the findings from these studies were used to aid physical therapy programs in their recruitment of students (Johanson, 2004; Johanson, 2007; Wilcox et al., 2005).

\section{Factors Influencing Social Workers}

Kindle and Colby (2008) studied the graduate school selection preferences of public university and private institution students in Master of Social Work (MSW) programs. With the imbalance between applicants and enrollment, their research focused on exploring the reasons MSW students applied to specific programs. Using a broad survey, Kindle and Colby (2008) investigated the differences between students at public universities and private institutions.

After piloting a seven item survey, more questions were added to capture the student's accounts of school selection (Kindle \& Colby, 2008). Then, the survey was distributed to deans and programs directors on the National Association of Deans and Directors of Schools of Social Work Listserv and forwarded to students. Incomplete surveys or surveys missing data were eliminated leaving 2,289 surveys complete. The response rate was $6.3 \%$ based 
on the 2007 enrollment statistic reported by the Council on Social Work Education (Kindle \& Colby, 2008).

The results of this study found that there were differences between public and private school MSW students. Public MSW students tended to be older, were less likely to relocate, and applied to one school. That school was generally close to home and affordable. In addition, they often attended the same school for their undergraduate degree, and were more concerned with location. Private MSW students were more concerned with reputation of the college/program, submitted more applications, got accepted into more schools, moved further from home, and reported more responses concerning employment (Kindle \& Colby, 2008).

In conclusion, it could be predicted that if a student moved to another city, was older, applied to one college that was close to home, was unable to relocate, and concerned about the cost of education, the student was likely to be enrolled at a public university. However, if the student reported receiving financial assistance, a small school preference, interest in a specific area, or the belief that a degree would increase job opportunity, the student was likely to be enrolled in a MSW program at a private institution (Kindle \& Colby, 2008).

\section{Factors Influencing Nurses}

Given the lack of male nursing students in the years prior to 1990 , Kippenbrock (1990) studied the small male population in nursing programs 
throughout the nation. At the time, many nursing programs focused their recruitment on males to address the decline in enrollment (Kippenbrock, 1990). Because previous research in nursing neglected to study this population, Kippenbrock found it important to investigate the variables that attracted male nursing students to select a particular program. Also, the findings would lead to better strategies to increase male nurses.

The survey instrument was developed using factors of influence pertaining to nursing students derived from the literature review. After the survey was validated by experts in the field, it was mailed to chief administrators at 486 nursing programs. After 279 baccalaureate nursing programs participated, the response rate was $66 \%$. It was found that $70 \%$ of schools made no effort to recruit males. While the average school had $5.3 \%$ males enrolled, $12 \%$ of nursing programs had none. There was a significant positive relationship between male application/enrollment and male faculty indicating male nursing students attended schools with more male faculty. Another strong correlation was found between application/enrollment and tuition, and room and board cost. Males had less chance of enrolling, if the cost of attendance was high. According to this research, the best strategy to increase male enrollment rates was to invite high school counselors to visit the campus (Kippenbroch, 1990).

In the twentieth century, nursing continues to be a female-dominated profession. Following a literature review regarding men in nursing, Meadus 
(2000) determined factors that deter males from nursing and recommended recruitment strategies to bridge the gender gap. Barriers included the following:

1. Historically, nursing was thought to be an extension of a woman's work.

2. The stereotype of nursing as a female occupation and male nurses being gay is still prevalent.

3. Images of women as nurses reinforce that stereotype.

4. No special incentives are offered to male nurses.

To recruit and retain men in nursing, Meadus (2000) suggested that nursing be marketed to men. High school counselors need to be educated to better inform young men about nursing careers. Moreover, to correct sexist language/images and the public perception, a public media campaign should be formed. The final recommendation was to improve the pay scale along with extending affirmative action to male nurses seeking employment (Meadus, 2000).

\section{Factors Influencing Physiotherapists}

Glover et al. (2008) studied the attitudes and perceptions of physiotherapy students as they chose to pursue an advanced degree. Unlike previous research, the authors took a qualitative approach. Nine physiotherapists (eight females and one male) pursing master's degrees participated in semi-structured interviews. The two major themes expressed were motivators and barriers (Glover et al., 2008). Glover and colleagues found motivating themes were 
internal, based on participant's feelings, or external, encouraged by another person or thing. In the following quotes, participants expressed professional/personal development that influenced them to pursue a master's degree:

Jim: "...I thought the studying as well as knowledge would actually improve handling skills..." (Glover et al., 2008, p.17).

Jackie: "I was hoping to be able to find out a bit more about approaches to physiotherapy under different models, look at what's best in terms of neurological treatment and things ... I hoped to be able to probe a bit more." (Glover et al., 2008, p.16).

Other physiotherapists mentioned support from peers, educators or family which was considered external motivations.

Elizabeth: "... I had one colleague who started the Masters module with me and she very much encouraged me to come along." (Glover et al., 2008, p.17).

External barriers manifested as people being unsupportive or challenging obstacles. Overall, the desire to develop was found to be the most influential internal motivator (Glover et al., 2008). 


\section{Factors Influencing Dental Hygienists}

Kanji, Sunell, Boschma, and Craig (2010) explored the experiences and motivating influences on Canadian dental hygienists with a dental hygiene diploma from accredited Canadian programs. Participants had practiced two years before going back to school to earn their baccalaureate degrees from a Canadian university. The qualitative nature of the study fostered an understanding from the perspectives of dental hygienists. Semi-structured interviews were analyzed using the 4-step Giorgi method (i.e., bracketing, intuiting, describing, and analyzing). All the dental hygiene students felt a bachelor's degree in dental hygiene would expand career opportunities. Some participants wanted to learn more and improve their self-confidence. These feelings explained the second theme, personal development (Kanji et al., 2010).

Regarding the third theme, remaining competitive, dental hygiene students stated they “...didn't want to be left behind” (Kanji et al., 2010, p. 150). Status and recognition emerged as the fourth theme where having the diploma was not as recognized as having a bachelor's degree. Although few participants reported seeking further education, they wanted to have the option later in life; thus, the theme of access to graduate education. Dental hygiene students felt they would get more respect with a degree. The final theme was third person influences, such as family, dental hygiene instructors or friends with degrees (Kanji et al., 2010). 
Looking into the experiences of dental hygiene students in bachelor's programs, Kanji et al. (2010) identified three common experiences: broad education, independent learning environment, and focus on critical thinking. In general, these students were pleased with the diversity of courses offered, challenged by the independent study, and believed they were better critical thinkers because they attended bachelor's programs (Kanji et al., 2010).

\section{Factors Influencing Marriage and Family Counselors}

Hertlein and Lambert-Shute (2007) studied factors marriage-and-family therapy (MFT) students consider important when choosing a graduate program and whether programs selected met their expectations. The study employed a mixed methods' research design that incorporated Likert-scale responses and open-ended responses in an online survey. The survey was distributed to 68 program directors, but only 18 confirmed they would forward it to students. As a result, the response rate was 26.4\% (Hertlein \& Lambert-Shute, 2007).

Hertlein and Lambert-Shute (2007) analyzed Likert responses according to the frequencies of number one ratings. Among the six factors, personal fit was the most important factor to $61.2 \%$ of master's students and $53.3 \%$ of doctoral students. There was a tie for the second most important factor between clinical work and funding; both yielded a $30.6 \%$ response rate. Twenty-four percent of doctoral students claimed that funding was the second most important factor. The faculty quality was rated third most important by $11.1 \%$ of doctoral students 
and fourth most important by master's students (Hertlein \& Lambert-Shute, 2007).

To gain insight into the experiences in MFT graduate programs, the survey featured open-ended responses. When asked if the program was meeting their expectations, $41 \%$ of students said their program was meeting their expectations, $51 \%$ of students said their program was exceeding their expectations, and $6 \%$ of students said their program was falling short of their expectations. When the doctoral students were asked the same question, $58 \%$ indicated their program was meeting their expectations, $27 \%$ indicated their program was falling short of their expectations, $11 \%$ indicated their program was exceeding their expectations, and $4 \%$ indicated their program was not meeting their expectations (Hertlein \& Lambert-Shute, 2007).

While Hertlein and Lambert-Shute (2007) claimed funding was important, it was not the most important factor to MFT students. To promote MFT graduate programs better, they recommended program directors invite students to campus; thus, students could experience how they would fit in.

\section{History of Athletic Training Education}

In 1950, the founding of the National Athletic Trainers' Association (NATA) led to athletic training education. William E. Newell is considered the founding father of athletic training education. He was an athletic trainer, but was concomitantly credentialed as a physical therapist. Newell also served as a role 
model leading many athletic trainers to continue their education in physical therapy. Once he was appointed National Secretary in the NATA, he sought to increase academic opportunities in athletic training (Miller, 1999). His committee worked to set standards and guidelines for athletic training education. At that time, there were no athletic training education programs for athletic trainers. Instead, athletic trainers utilized a book written by S. E. Bilik called the Trainer's Bible (as cited in Prentice, 2006).

The first athletic training curriculum model was approved in 1959. The curriculum included courses that were prerequisites for physical therapy programs because Newell encouraged students to continue their education in physical therapy, as he had done (Delforge \& Behnke, 1999). Also, it was thought that continuing education in physical therapy made an athletic trainer more marketable. Since there was a demand for athletic trainers in secondary school settings, the curriculum focused on obtaining teaching credentials and recommended the athletic trainer be a teacher-trainer (Perrin, 2007; Delforge \& Behnke, 1999). Now, the athletic trainer could provide health care and teach physical education or health education (Perrin, 2007).

Later, in 1969, the Committee on Gaining Recognition was re-named the Professional Education Committee and a Committee on Certification was organized. In that same year, the first undergraduate programs, now referred to as Professional Athletic Training Education Programs (ATEPs), were 
established; they included Mankato State College, Indiana State University, Lamar Tech, and University of New Mexico (Perrin 2007).

Shortly after the establishment of ATEPs, master's level programs began to emerge. Like other health care professionals, athletic trainers now had the option of continuing education in their field rather than pursuing a degree in physical therapy. As mentioned earlier, these programs are referred to as PostProfessional Athletic Training Education Programs (PATEPs). There are currently 15 accredited programs in the nation. Indiana State University and University of Arizona were the first programs accredited (Delforge \& Behnke, 1999).

Just as the educational programs were developing, a certification exam was created. By the 1970s, the first certification exam was administered; today the exam is known as the Board of Certification Exam (Delforge \& Behhnke, 1999). However, there were alternate avenues an athletic trainer could choose to become certified. The ways an athletic trainer could become certified included (1) completing an apprenticeship, (2) graduating from an ATEP or PATEP, (3) continuing education in physical therapy, or (4) five years as an "actively engaged" athletic trainer (Delforge \& Behnke, 1999, p.55). Typically, the fourth option was known as the grandfather clause; it applied to athletic trainers who were older and had been practicing for more than five years. Even with 
accredited graduate programs specializing in athletic training, the third option still encouraged athletic trainers to pursue further study in physical therapy.

The next significant change focused on courses athletic trainers were required to take. Since the demand for jobs in high school settings decreased, there was less need to acquire teaching credentials. Consequently, courses were limited to those pertaining to athletic training and those of other allied health professions. Chemistry and physics classes were removed because they were prerequisites for physical therapy, but the transformation did not stop there.

Coaching and exercise classes, specific to a physical education major, were also removed (Delforge \& Behnke, 1999; Perrin, 2007). After the athletic training curriculum had been revised, it was introduced as an academic major at many colleges and universities.

\section{Summary}

Many health care professions have studied the factors that affect student enrollment in graduate programs. In physical therapy, it was seen that minority students were influenced by cost, ethnic/culture and gender issues, and faculty relations (Johanson, 2007; Wilcox et al., 2005). Also, the higher the mother's education, the more likely the student was to pursue a DPT program rather than a MPT program (Johanson, 2004). Kindle and Colby (2008) created a predictive model based on the different factors influencing students of social worker to attend private schools and public universities. 
In nursing studies, there was a strong correlation found among male students and male faculty suggesting that male nursing students selected programs with male faculty (Kippenbrock, 1990). Another nursing study claimed that the marketing and public perception of the occupation deter males from studying nursing (Meadus, 2000). Both nursing studies advocated for better education of high school counselors assisting young men in nursing careers (Kippenbrock, 1990; Meadus, 2000).

Glover et al. (2008) conducted a qualitative study exploring the experiences of physiotherapy students continuing their education. While the desire to develop was found to be the most influential factor, unsupportive people and challenging obstacles were expressed as barriers. Dental hygiene students also found the desire to develop important, but marketability of the degree was the most influential factor (Kanji et al., 2010). Marriage and family therapy students ranked personal fit as the most important factor (Hertlein \& LambertShute, 2007). As a result, program directors were encouraged to include campus visits in their recruitment to allow the students to experience the graduate program. Overall, studies like these were used to recommend better recruitment strategies.

The profession of athletic training has evolved drastically and continues to transform. To keep producing competent athletic trainers, the profession has aligned the educational standards with other health care professions and 
developed graduate programs. However, students are still studying in other areas when there are options for an advanced degree in athletic training. Research on the factors influencing athletic training students is warranted because it has not been studied and identifying the factors may lead to better recruitment and retaining more students in the field. As revealed in the literature review, other health care professions have conducted similar research as a strategy to increase student enrollment (Kanji et al., 2010; Kindle \& Colby, 2008; Kippenbrock, 1990; Glover et al., 2008; Hertlein \& Lambert-Shute, 2007; Johanson, 2004; Johanson, 2007; Meadus, 2000; Wilcox et al., 2005). As a result, these research studies exposed the motivating factors as well as barriers that deter students from selecting graduate programs. In all, this literature review has revealed a need for research on the factors that influence athletic training students' selection of graduate programs. 


\section{Chapter 3}

\section{Methods}

The purpose of this study was to determine the factors influencing athletic training students' selection of graduate programs and to further investigate the relationships among the factors and age, ethnicity, and gender. A pilot study was conducted to establish methodologically sound procedures. Chapter 3 contains the methods and procedures involved in this study. The chapter is divided into six sections: (1) Participants, (2) Instrumentation, (3) Pilot Study, (4) Procedures, (5) Research Design, (6) Data Analysis. Following the methodology, a summary is presented.

\section{Participants}

Before conducting the study, the Humans Subjects-Institutional Review Board of San José State University approved the research. Similar to previous research, this study targeted newly accepted and currently enrolled graduate athletic training students (Johanson, 2004; Johanson 2007). These students were preferred over undergraduate students given that they had already undergone the process of selection and committed to a graduate program. Out of 424 surveys started, 410 were completed. There were twice as many females $(n=272 ; 66.3 \%)$ than there were males $(n=138 ; 33.7 \%)$. While the participants were largely Caucasian/White, ethnic minorities accounted for $16.1 \%(n=66)$ of the population. Eighty-nine percent of the students were less than 27 years old. 
In addition, more than half the students were single, without dependents, NATA members, and attended graduate schools out-of-state.

The NATA's Career Center was useful in finding schools with graduate athletic training students. Other colleges with eligible students were found through the Pl's network and an internet search. The internet search consisted of checking a college's website for program directors' (PDs), head athletic trainers' (hATs) and graduate students' contact information.

To determine the program director's email address, the athletic training department homepage was located. In the absence of the PD's address, the head athletic trainer's address was located by searching the athletics department's homepage. Usually, the contact information of hATs was found on the staff directory page or sports medicine page. Occasionally, the students' email addresses were listed, too. Once all the email addresses were found, they were compiled into four lists: (1) students attending PATEPs, (2) students attending other graduate program, (3) PATEP PDs, and (4) all other PDs/hATs. Although, PDs and hATs did not complete the survey, they were critical to the process as they distributed the survey to their students.

\section{Instrumentation}

The survey was adapted from research from the literature review (Abernethy, 1996; Johanson, 2004; Johanson, 2007; Wilcox et al., 2005). Before the survey was distributed, it was placed on SurveyMonkey.com® 
(SurveyMonkey.com, LLC, Palo Alto, USA) because online databases have the ability to solicit widespread participation without mailing fees. It included a letter of consent informing the participants of their rights. In anticipation that some students might receive survey notifications from more than one source, a line was added to the consent letter asking students who had already participated to exit the survey. In addition, students were informed of their eligibility in the consent letter. Only newly accepted students, currently enrolled students, and recent athletic training graduates were eligible to participate.

In creating the survey, the physical therapy articles were found to be the most useful as they were more closely related to athletic training (Johanson, 2004; Johanson, 2007; Wilcox et al., 2005). To examine the demographics of the graduate athletic training student population, information regarding gender, age, ethnicity, marital status, dependents, location, graduate program, NATA membership and parent's education was obtained. These questions were answered with closed-ended responses.

Then, a list was assembled of factors derived from Johanson (2004), Johanson (2007), and Wilcox et al., (2005). As Likert-scale responses are the most widely accepted form of psychological assessment, the second portion of the survey incorporated questions with a 3-point Likert-scale. The scale included responses not important $(\mathrm{Nl}=1)$, moderately important $(\mathrm{Ml}=2)$, very important $(\mathrm{VI}=3)$, and not applicable $(\mathrm{N} / \mathrm{A}=0)$ if a factor irrelevant to the student. The 
factors of influence were divided into specific categories: socioeconomic, geographic, diversity, program/faculty, college/university, and motivational. Each category was placed on its own page in the survey. (A classification of potential factors of influence by categories may be seen in Table 1. on the next page.)

Qualitative responses, the final section of the survey, allowed students to elaborate on particular factors as well as address factors not listed. Just as Bishop et al. (2008) were able to explore barriers physiotherapists faced when deciding to continue their education, it was hoped that students would reveal barriers in their open-ended responses in this research. There was no limit as to how much the students expressed on the open-ended responses. In total, there were five questions; all were optional. The survey concluded with a thank-you page. (A copy of the survey may be seen in Appendix F.)

\section{Pilot Study}

A pilot study was conducted using graduate athletic training students in San José State University's Graduate Athletic Training Education Program. The pilot sample of 25 students was convenient and willing to complete the survey.

The pilot study served to ascertain the time to complete the survey, check for clarity of questions, and to determine criterion-related validity (Turocy, 2002). Ideally, the pilot study justified removing, adding, or altering questions that were confusing or unimportant. 


\section{Table 1}

\section{Classification of Potential Factors of Influence by Categories}

\begin{tabular}{|c|c|c|c|c|c|}
\hline \multicolumn{6}{|c|}{ Categories of Influence } \\
\hline Socioeconomic & Geographic & Diversity & Program/Faculty & College/University & Motivational \\
\hline Cost/Affordability & $\begin{array}{c}\text { Distance from } \\
\text { Permanent } \\
\text { Home }\end{array}$ & $\begin{array}{c}\text { Faculty Similar in } \\
\text { Ethnicity }\end{array}$ & Accreditation Status & $\begin{array}{c}\text { Prestige } \\
\text { (or General University } \\
\text { Reputation) }\end{array}$ & $\begin{array}{c}\text { Self-Determination/ } \\
\text { Improvement }\end{array}$ \\
\hline $\begin{array}{l}\text { Amount of Financial } \\
\text { Aid Available }\end{array}$ & $\begin{array}{c}\text { Distance from } \\
\text { Undergraduat } \\
\text { e School }\end{array}$ & $\begin{array}{c}\text { Campus Activities } \\
\text { Related to } \\
\text { Ethnic/Cultural } \\
\text { Background }\end{array}$ & Degree Conferred & $\begin{array}{l}\text { Size/Type of } \\
\text { Institution }\end{array}$ & $\begin{array}{c}\text { Seeking a } \\
\text { Challenge/Exciting } \\
\text { Work }\end{array}$ \\
\hline $\begin{array}{c}\text { Graduate Assistant } \\
\text { Offered }\end{array}$ & $\begin{array}{l}\text { Size of the } \\
\text { City/Town }\end{array}$ & $\begin{array}{c}\text { Diversity of Student } \\
\text { Body }\end{array}$ & $\begin{array}{l}\text { Admission } \\
\text { Requirements } \\
\text { (GREs, GPA, etc.) }\end{array}$ & $\begin{array}{l}\text { Marketability of } \\
\text { Degree Received }\end{array}$ & Aspiration \\
\hline $\begin{array}{c}\text { Teaching Assistantship } \\
\text { Offered }\end{array}$ & Living Cost & $\begin{array}{l}\text { Students Similar in } \\
\text { Ethnicity/Gender }\end{array}$ & $\begin{array}{l}\text { Student/Faculty } \\
\text { Ratio or Class Size }\end{array}$ & $\begin{array}{l}\text { Prestige of Sports } \\
\text { (Championship Titles } \\
\text { Won) }\end{array}$ & $\begin{array}{c}\text { Sense of } \\
\text { Achievement }\end{array}$ \\
\hline $\begin{array}{c}\text { Grants/ } \\
\text { Scholarship }\end{array}$ & Crime Rate & $\begin{array}{c}\text { Faculty of Same } \\
\text { Gender }\end{array}$ & Length of Program & $\begin{array}{c}\text { Perceived Quality of } \\
\text { Education }\end{array}$ & $\begin{array}{l}\text { Importance of } \\
\text { Education }\end{array}$ \\
\hline $\begin{array}{c}\text { Parents' Education } \\
\text { Level }\end{array}$ & $\begin{array}{l}\text { Weather } \\
\text { Condition }\end{array}$ & Campus/Student Life & $\begin{array}{c}\text { Clinical Site/Sport } \\
\text { Assignment }\end{array}$ & $\begin{array}{l}\text { Attractiveness/ } \\
\text { Appearance }\end{array}$ & Recognition \\
\hline $\begin{array}{l}\text { Extended Non-Familial } \\
\text { Network (ATEP PD, } \\
\text { ACI, Peers, Alumni) }\end{array}$ & Location & & $\begin{array}{l}\text { Prestige of Faculty } \\
\text { (Research \& } \\
\text { Publication } \\
\text { Activities) }\end{array}$ & $\begin{array}{c}\text { Campus Facilities } \\
\text { (Student Union, } \\
\text { Library, Sport } \\
\text { Venues, etc.) }\end{array}$ & $\begin{array}{c}\text { Ability to Contribute } \\
\text { to Profession }\end{array}$ \\
\hline Family & & & Prestige of Program & Size of Enrollment & $\begin{array}{l}\text { Desire for } \\
\text { Knowledge }\end{array}$ \\
\hline
\end{tabular}

Note. These categories have been derived from Johanson (2004), Johanson (2007), and Wilcox et al., (2005). 
An analysis was included to ensure the reliability of each factor of influence. Factors ranked as not important by more than $50 \%$ of the students were removed from the survey. The survey tool underwent re-evaluation following the pilot study and revisions based on data and feedback from students. The final version of the survey was assessed by two experts for face, construct, and content valid (Turocy, 2002). The experts had an extensive background in research and athletic training education and included: Holly Brown, Clinical Coordinator of Professional Athletic Training Education Program at San José State University and Dr. KyungMo Han, Program Director of Professional Athletic Training Education Program at San José State University.

\section{Procedures}

This study was conducted from June to August of 2011. During the summer months, many educators and students have time off; therefore, it was an ideal time to complete a survey. Although all students are not members of the NATA, there were 378 graduate athletic training students reported in June 2011 NATA's membership statistics. Consequently, the goal was set to collect a minimum of 300 responses. First, the survey was sent to 153 PDs and hATs. The selected PDs and hATs were found through an internet search of colleges and through the NATA's Career Center. They were recruited with an email that introduced the PI, gave a brief synopsis of the study, and requested their involvement (a copy of the letter may be seen in Appendix B). 
Some PDs responded and confirmed the number of students to whom they forwarded the survey. Other PDs and hATs did not reply as they were only asked to forward the survey. Although involving these people of authority to encourage student participant was helpful, a true response rate was impossible to determine because there was no way of knowing exactly how many students were forwarded the survey relative to those responding. A week later, the PDs and hATs were sent a reminder email to forward the survey again (a copy of the letter may be seen in Appendix C).

The graduate students on the list compiled by the PI were contacted directly via email addresses made public on their school's website. Like the letter to the PDs and hATs, the students' letter introduced the PI and the study followed by a hyperlink to the survey (a copy of the letter may be seen in Appendix D). Once the student clicked the link, the letter of consent informed the students of their rights as mandated by the Humans Subjects-Institutional Review Board of San José State University. Participants in the study were made aware of the following (1) their participation was voluntary and there were no foreseeable risks or discomforts to them through participating, (2) nothing adverse would result from a decision not to participate nor finish the survey, (3) the results might be published, however no identifying information would be included linking them to the study. As the participants began the survey, they consented to participate in the study. Unlike the PDs and hATs, graduate 
students received two email reminders per week (a copy of the letter may be seen in Appendix E).

If there was a lack of surveys returned resulting in a low response goal, the PI had a contingency plan. Since social media had proved to be such a popular and effective means of communication among students, it was utilized in the contingency plan (Johnston, 2010). The PI recruited students and distributed the survey through social media and recruited students while attending the NATA Convention (June 18-25, 2011). The PI would also take advantage of NATA's Survey Research Service which would email the survey to 1,000 students at no cost. In the worst case scenario, the survey would be printed and mailed to PDs/hATs as a last resort to elicit participation.

Although, the minimum response goal was reached by mid-July, data was collected until August 1, 2011. The PI did resort to measures of the contingency plan to surpass the intended response goal. Approximately 287 graduate athletic training students were emailed by the $\mathrm{PI}$ at the address listed on their university website. Ten emails bounced and eight students chose to opt-out of the study. Of the 269 left to participate, a total of 105 took part in the survey (39\% response rate). The NATA Survey Research Service emailed approximately 1,000 certified students. Of the 1,000 students emailed by the NATA Survey Research Service, 187 participated in the survey (18.7\% response rate). An additional 42 students 
were recruited over social media and at the 2011 NATA Convention. In all, 424 surveys were started and 410 were completed.

\section{Research Design}

The research design was a web-based survey to be completed once by as many students as possible across the nation. It measured the frequencies, means, medians, and percentages of factors of influence as determined by the students. The effects of gender, age, and ethnicity were examined using cross tabulations. These variables represented the independent variables, while the factors of influences were the dependent variables. Overall, this study may be viewed as a descriptive, qualitative study.

\section{Data Analysis}

Upon completion of the survey, the data from SurveyMonkey.com ${ }^{\circledR}$ (SurveyMonkey.com, LLC, Palo Alto, USA) were examined using Statistical Package for the Social Sciences (SPSS) version 19.0. The statistical analysis began with demographic responses to report descriptive statistics. Frequencies of ratings and percentages were used to determine the most influential factors. Then cross tabulations were applied to identity correlations between those factors of influence and gender, age, and ethnicity.

The goal of the qualitative section was to facilitate insight and a deeper understanding of the influences on the students' decisions (Pitney \& Parker, 
2002). There was no limit on typed responses. The open-ended responses were reviewed, defined, and clustered for major themes (Pitney \& Parker, 2001; Seegmiller, 2006). The themes underwent peer-reviews with an advisor, Holly Brown, a specialist in qualitative research; the nature of the survey did not allow for member checks or triangulation to establish the trustworthiness of quotes (Pitney \& Parker, 2001).

\section{Summary}

An exhaustive literature review identified previous studies on factors influencing students. As well, the methodology for this investigation was modeled after those studies (Johanson, 2004; Johanson, 2007; Wilcox et al., 2005). A mixed-methods experimental design, featuring close-ended and openended questions, was employed to investigate the perceptions of hundreds of students, rather than a select few students using interviews. In short, the main participants were graduate athletic training students. Program directors and head athletic trainers were approached to help facilitate the study. Subsequently, the survey was forwarded to the students through an email from their program director or head athletic trainer. Other students received the survey directly from the PI or the NATA Survey Research Service. The first part of the survey included the demographic section, followed by Likert-scale responses inquiring about the influence of each factor, and concluded with openended questions. 


\section{Chapter 4}

\section{Results}

The purpose of this study was to determine the factors that influence athletic training students' selection of graduate programs. Additionally, this study sought to examine the effects of gender, age, and ethnicity. As previously noted, it was imperative to distribute the survey over the internet to solicit a broad-based national response. Understanding how athletic training students select graduate programs may be useful to athletic training educators and can improve recruitment strategies to retain more students in the profession. Chapter 4 contains the results of the survey and is divided into six sections: (1) Demographic Statistics, (2) Hypothesis, (3) Sub-Hypothesis on Gender, (4) SubHypothesis on Age, (5) Sub-Hypothesis on Ethnicity, (6) Analysis of Qualitative Responses. Following the results, a chapter summary is presented.

\section{Demographic Statistics}

There were 424 surveys submitted and 410 surveys completed. Nearly twice as many females $(66.3 \% ; n=272)$ than males $(33.7 \% ; n=138)$ participated. The sample was $83.9 \%$ Caucasian/white $(n=344), 5.4 \%$ Asian/Pacific Islander $(n=22), 3.9 \%$ African American/black ( $n=16), 3.4 \%$ bi/multi-racial $(n=14), 3.2 \%$ Latino/Hispanic $(n=13)$, and .2\% American Indian/Native American $(n=1)$. The largest group (46.6\%; $n=191)$ of the graduate students was between 24 and 27

years of age. Following close behind, $44.1 \%(n=181)$ were less than 24 years of 
age. Students older than 27 years accounted for $9.3 \%(n=38)$ of participants. A vast majority of students indicated their marital status was single $(91.2 \% ; n=374)$. A few were either divorced $(.5 \% ; n=2)$ or married $(8.3 \% ; n=34)$. When asked about dependents, $97.8 \%(n=401)$ reported none.

Responses came from graduate athletic training students all over the country and from all NATA districts, including 15 international students. More than half of students $(60.7 \% ; n=249)$ attended graduate programs out-of-state, and $38.5 \%(n=158)$ of students remained in their state of permanent residence. Most of the respondents $(89.0 \% ; n=365)$ were members of the NATA. Also, students indicated the type of graduate program they attended as follows: GATEPs (34.5\%; $n=142)$, health science programs (23.2\%; $n=95)$, PATEPs (20.5\%; $n=84)$, non-health science programs $(12.0 \% ; n=49)$, ELMs $(8.0 \% ; n=33)$, and $1.7 \%(n=7)$ did not know how to classify their graduate program.

With regard to the parents' level of education, similar numbers of mothers (34.1\%; $n=140)$ and fathers $(31.1 \% ; n=128)$ had earned a bachelor's degrees. More fathers $(4.6 \% ; n=19)$ had doctoral degrees than mothers $(1.5 \% ; n=6)$. Yet, more mothers $(13.9 \% ; n=57)$ possessed an associate's degree than fathers (8.0\%; $n=33)$. Additionally, more students' fathers seemed to have less than a high school education $(2.7 \% ; n=11)$ than mothers $(.5 \% ; n=2)$. Excluding the parents' level of education, a brief summary of the demographic statistics is presented in Table 2 (shown on the next page). 
Table 2

Demographic Statistics of Participants

\begin{tabular}{|c|c|c|}
\hline \multirow[t]{2}{*}{ Characteristics } & \multicolumn{2}{|c|}{ Number of Participants } \\
\hline & $\mathrm{n}=\mathbf{4 1 0}$ & Percent \\
\hline \multicolumn{3}{|l|}{ Gender } \\
\hline Males & 138 & $33.7 \%$ \\
\hline Females & 272 & $66.3 \%$ \\
\hline \multicolumn{3}{|l|}{ Ethnicity } \\
\hline American Indian/Native American & 1 & $.2 \%$ \\
\hline Asian/Pacific Islander & 22 & $5.4 \%$ \\
\hline African American/Black & 16 & $3.9 \%$ \\
\hline Bi/Multi-racial & 14 & $3.4 \%$ \\
\hline Caucasian/White & 344 & $83.9 \%$ \\
\hline Latino/Hispanic & 13 & $3.2 \%$ \\
\hline \multicolumn{3}{|l|}{ Age } \\
\hline Less than 24 years & 181 & $44.1 \%$ \\
\hline Between 24 and 27 years & 191 & $46.6 \%$ \\
\hline Older than 27 years & 38 & $9.3 \%$ \\
\hline \multicolumn{3}{|l|}{ Marital Status } \\
\hline Single & 374 & $91.2 \%$ \\
\hline Married & 34 & $8.3 \%$ \\
\hline Divorced & 1 & $.5 \%$ \\
\hline \multicolumn{3}{|l|}{ Do you have any dependents? } \\
\hline Yes & 9 & $2.2 \%$ \\
\hline No & 401 & $97.8 \%$ \\
\hline \multicolumn{3}{|l|}{ Location of Graduate Program } \\
\hline In-state & 158 & $38.5 \%$ \\
\hline Out-of-state & 249 & $60.7 \%$ \\
\hline Missing Responses & 3 & $.7 \%$ \\
\hline \multicolumn{3}{|l|}{ Type of Program } \\
\hline PATEP & 84 & $20.5 \%$ \\
\hline GATEP & 142 & $34.6 \%$ \\
\hline ELM & 33 & $8.0 \%$ \\
\hline Health Science & 95 & $23.2 \%$ \\
\hline Non-Health Science & 49 & $12.0 \%$ \\
\hline Unsure & 7 & $1.7 \%$ \\
\hline
\end{tabular}

\section{Hypotheses}

A Likert-scale section followed the demographic questions in which students rated the influence of 41 factors as being very important (VI), 
moderately important (MI), not important (NI), or not applicable (N/A). The graduate assistantship appeared to be the most important factor influencing $(83.9 \%=\mathrm{Vl} ; \mathrm{n}=344)$ students to select their graduate programs. Within the category of socioeconomic factors, cost of education/affordability was considered very important to $53.7 \%(n=220)$. Though similar to the graduate assistantship, the teaching/research assistantship was viewed as less important. Forty percent of participants thought it was "not important." The influence of family $(40.2 \%=\mathrm{Ml}$; $n=164)$, the program director $(40.2 \%=M l ; n=165)$, and the approved clinical instructor $(45.4 \%=\mathrm{Ml} ; \mathrm{n}=186)$ yielded the most responses in the "moderately important" category. The influence of alumni relations $(47.3 \%=\mathrm{NI} ; \mathrm{n}=194)$ was not found to be an important factor to students.

Factors in the geographic category did not appear to be very important among the students. Cost of living received the most rankings as moderately important from $54.9 \%(n=225)$ of students. Other factors, location of graduate program (45.9\%=Ml; $n=188)$, size of city/town $(45.1 \%=M l ; n=185)$, and distance from home $(40.5 \%=\mathrm{Ml} ; \mathrm{n}=166)$, generated mostly "moderately important" responses, but by less than $50 \%$ of respondents. Factors such as crime rate $(45.1 \%=\mathrm{Nl} ; \mathrm{n}=185)$ and weather $(44.9 \%=\mathrm{NI} ; \mathrm{n}=184)$ were not considered important to students.

Responses in the diversity category were generally not important to the participants. The following factors were perceived as the least important overall: 
faculty similar in ethnicity $(88.3 \%=\mathrm{NI} ; \mathrm{n}=362)$, faculty of same gender $(91.7 \%=\mathrm{NI}$; $n=376$ ), campus activities related to student's ethnic/cultural background $(88.3 \%=\mathrm{NI} ; \mathrm{n}=362)$, diversity of student body $(76.6 \%=\mathrm{NI} ; \mathrm{n}=314)$, students similar in gender/ethnicity $(87.8 \%=\mathrm{NI} ; \mathrm{n}=360)$ and student life $(56.6 \%=\mathrm{NI}$; $n=232)$, On average, $86.8 \%$ students $(n=356)$ perceived these factors as not important.

Within the program/faculty category, accreditation status, degree conferred, and admission requirements received the highest percentages for very important. Fifty-seven percent of participants $(n=233)$ felt the degree conferred was very important, followed by the program's status of accreditation $(53.7 \%=\mathrm{VI}$; $\mathrm{n}=220$ ). It should be noted that status of accreditation was not delimited to CAATE-accredited or NATA-accredited athletic training programs. Taking into consideration the Graduate Records Examination and grade point average, admission requirements were found to be moderately important to $51.5 \%$ of students $(n=211)$.

The college/university category had more factors perceived to be very important than any other category in the survey. Students identified the quality of education $(56.3 \%=\mathrm{VI} ; \mathrm{n}=231)$ and the marketability of the degree $(51.0 \%=\mathrm{VI} ; \mathrm{n}=$ 209) as the only "very important" factors. Though ranked moderately important, campus facilities (referring to the student union, library, dining halls, parking, and sport venues) were considered a key factor to $58.3 \%(n=239)$ of respondents. All 
other factors received less than sixty percent of responses and included: prestige of the university $(58.3 \%=\mathrm{Ml} ; \mathrm{n}=239)$, type of institution (referring to Carnegie classification) (58.3\%=Ml; $n=239)$, appearance/attractiveness of campus $(57.3 \%=M l ; n=235)$, and prestige of athletics $(42.4 \%=M l ; n=174)$. Size of enrollment was the only factor viewed as generally not important by $46.1 \%$ $(n=189)$ of students.

In addition to the graduate assistantship factor, other factors in the motivational category received high percentages of "very important" responses. As a result, all of these factors were collectively grouped and referred to as motivational factors (see Table 3 below). These factors, when combined, were

Table 3

Factors Ranked as Generally Very Important

\begin{tabular}{lll}
\hline \multicolumn{1}{c}{ Factors } & $\mathbf{n = 4 1 0}$ & Percent \\
\hline Graduate Assistantship & 344 & $83.9 \%$ \\
Motivational Category & & \\
$\quad$ Self-Improvement & 338 & $82.4 \%$ \\
$\quad$ Desire for Knowledge & 320 & $78.0 \%$ \\
$\quad$ Ability to Contribute to Profession & 283 & $69.0 \%$ \\
$\quad$ Aspiration & 264 & $64.4 \%$ \\
$\quad$ Recognition & 192 & $46.8 \%$ \\
Degree Conferred & 233 & $56.8 \%$ \\
Perceived Quality of Education & 231 & $56.3 \%$ \\
Status of Accreditation & 220 & $53.7 \%$ \\
Cost/Affordability & 220 & $53.7 \%$ \\
Marketability & 209 & $51.0 \%$ \\
\hline
\end{tabular}

found to be the second most influential factor. Specifically, students rated the factors as follows: self-improvement $(82.4 \%=\mathrm{Vl} ; \mathrm{n}=338)$, the desire for knowledge $(78 \%=\mathrm{Vl} ; \mathrm{n}=320)$, ability to contribute to profession $(69 \%=\mathrm{VI} ; \mathrm{n}=283)$, 
and aspiration $(64.4 \%=\mathrm{V} ; \mathrm{n}=264)$. Among the motivational factors, recognition was the only factor not rated as generally very important. Forty-seven percent ( $n=192)$ of respondents found recognition to be moderately important.

Sub-hypothesis on gender. Many of the differences observed between males and females pertained to influence of the ATEP program director and geography (see Table 4 below). More females $(42.3 \%=M l ; n=115)$ thought the ATEP program director was moderately important in their decision. Male students were split; $36.2 \%(n=50)$ felt the program director was not important, but the same amount thought the program director was moderately important. Within the geographic category, females showed more interest in the distance of the program from home $(42.0 \%=M l ; n=114)$, size of city/town $(47.4 \%=M l ; n=129)$, and weather conditions $(47.4 \%=\mathrm{Ml} ; \mathrm{n}=129)$ than did males. Male participants found distance of the program from home $(42.8 \%=\mathrm{Nl} ; \mathrm{n}=59)$, size of the city/town $(51.4 \%=\mathrm{Nl} ; \mathrm{n}=71)$, and weather conditions $(50.0 \%=\mathrm{Nl} ; \mathrm{n}=69)$ as not important.

Although men did not perceive crime rate as an important factor, women did. Forty-two percent of women indicated crime rate was not important $(n=116)$ and moderately important $(n=115)$. The prestige of athletic teams was the only factor where both genders showed particularly similar response rates with $42 \%$ of males and $42 \%$ of females agreeing that it was moderately important. Lastly, the marketability of the degree was more important to females $(54.0 \%=\mathrm{VI} ; \mathrm{n}=147)$ than it was to males $(48.6 \%=\mathrm{Ml} ; \mathrm{n}=66)$. 
Table 4

Differences Between Males and Females

\begin{tabular}{|c|c|c|c|c|}
\hline \multirow[t]{2}{*}{ Factors } & \multicolumn{2}{|c|}{ Females } & \multicolumn{2}{|c|}{ Males } \\
\hline & $n=272$ & Percent & $n=138$ & Percent \\
\hline \multicolumn{5}{|l|}{ ATEP Program Director } \\
\hline Very Important & 54 & $19.9 \%$ & 30 & $21.7 \%$ \\
\hline Moderately Important & 115 & $42.3 \%$ & 50 & $36.2 \%$ \\
\hline Not Important & 75 & $27.6 \%$ & 50 & $36.2 \%$ \\
\hline N/A & 28 & $10.3 \%$ & 8 & $5.8 \%$ \\
\hline \multicolumn{5}{|l|}{ Size of City/Town } \\
\hline Very Important & 34 & $12.5 \%$ & 11 & $8.0 \%$ \\
\hline Moderately Important & 129 & $47.4 \%$ & 56 & $40.6 \%$ \\
\hline Not Important & 106 & $39.0 \%$ & 71 & $51.4 \%$ \\
\hline $\mathrm{N} / \mathrm{A}$ & 3 & $1.1 \%$ & 0 & $0 \%$ \\
\hline \multicolumn{5}{|l|}{ Weather } \\
\hline Very Important & 24 & $8.8 \%$ & 18 & $13.0 \%$ \\
\hline Moderately Important & 129 & $47.4 \%$ & 51 & $37.0 \%$ \\
\hline Not Important & 115 & $42.3 \%$ & 69 & $50.0 \%$ \\
\hline $\mathrm{N} / \mathrm{A}$ & 4 & $1.5 \%$ & 0 & $0 \%$ \\
\hline \multicolumn{5}{|l|}{ Crime Rate } \\
\hline Very Important & 34 & $12.5 \%$ & 8 & $5.8 \%$ \\
\hline Moderately Important & 115 & $42.3 \%$ & 61 & $44.2 \%$ \\
\hline Not Important & 116 & $42.6 \%$ & 69 & $50.0 \%$ \\
\hline N/A & 7 & $2.6 \%$ & 0 & $0 \%$ \\
\hline \multicolumn{5}{|l|}{ Marketability } \\
\hline Very Important & 147 & $54.0 \%$ & 62 & $44.9 \%$ \\
\hline Moderately Important & 101 & $37.1 \%$ & 66 & $47.8 \%$ \\
\hline Not Important & 23 & $8.5 \%$ & 10 & $7.2 \%$ \\
\hline$N / A$ & 1 & $.4 \%$ & 0 & $0 \%$ \\
\hline
\end{tabular}

Sub-hypothesis on age. The older participants, age 27 years and older, accounted for $9.3 \%(n=38)$ of responses. These students were more likely to select a program in-state and ranked the location of the graduate program as being very important $(52.6 \% ; n=20)$ while the other groups yielded lower percentages of very important responses (as presented in Table 5 on page 51). However, the distance of the graduate school from home was not as important to older students $(47.4 \%=\mathrm{NI} ; \mathrm{n}=18)$ as it was to younger students $(43.0 \%=\mathrm{Ml}$; 
$n=160$ ). With regard to the crime rate of an area, older respondents were equally divided; $42.1 \%(n=16)$ indicated crime rate was not important or moderately important. Weather was another factor of interest to older students $(44.7 \%=\mathrm{Ml}$; $n=17)$; the younger age groups both felt it was generally not important $(47.0 \%=\mathrm{Nl} ; \mathrm{n}=171)$. The mature age group found admission requirements $(44.7 \%=\mathrm{VI} ; \mathrm{n}=17)$ and the length of the program $(50.0 \%=\mathrm{Vl} ; \mathrm{n}=19)$ very important compared to younger groups. Younger respondents reported generally moderate importance regarding the length of the program $(46.0 \%=\mathrm{Ml} ; \mathrm{n}=171)$ and admission requirements $(53.7 \%=\mathrm{Ml} ; \mathrm{n}=196)$. Additionally, the student-tofaculty ratio $(39.5 \%=\mathrm{NI} ; \mathrm{n}=15)$ and prestige of the athletic teams $(42.1 \%=\mathrm{NI}$; $\mathrm{n}=16$ ) was of relatively little importance to older participants.

Participants age 24 to 27 years old, were the largest group with $46.6 \%$ $(n=191)$ of responses. Forty-seven percent of these participants $(n=90)$ indicated that the rate of crime was not an important factor while the other groups expressed it was moderately important. Of the older students, $42.1 \%(n=16)$ claimed crime was moderately important while $47.1 \%(n=90)$ of middle age students agreed. Also, middle age respondents appeared divided on the importance of the prestige of the institution's athletic teams, with $37 \%$ of ratings for not important $(n=71)$ and moderately important $(n=72)$.

Those younger than 24 years old, the youngest age group, consisted of $44.1 \%(n=181)$ of responses. These students were more likely to attend 
graduate programs out-of-state $(68.5 \% ; n=124)$. In addition, the younger

students took more interest in the size of the city/town (49.7\%=Ml; $n=90)$.

\section{Table 5}

\section{Differences Between Age Groups}

\begin{tabular}{lrrrrrr}
\hline Factor & \multicolumn{2}{c}{$<\mathbf{2 4}$ yrs } & \multicolumn{2}{c}{$\mathbf{2 4 - 2 7 y r}$} & \multicolumn{2}{c}{$>\mathbf{2 7 y r}$} \\
\hline & $\mathrm{n}=181$ & Percent & $\mathrm{n}=191$ & Percent & $\mathrm{n}=38$ & Percent \\
Location of Program & & & & & & \\
Very Important & 60 & $33.1 \%$ & 67 & $35.1 \%$ & $\mathbf{2 0}$ & $\mathbf{5 2 . 6 \%}$ \\
Moderately Important & $\mathbf{8 6}$ & $\mathbf{4 7 . 5 \%}$ & $\mathbf{9 1}$ & $\mathbf{4 7 . 6 \%}$ & 11 & $28.9 \%$ \\
Not Important & 34 & $18.8 \%$ & 33 & $17.3 \%$ & 7 & $18.4 \%$ \\
N/A & 1 & $.6 \%$ & 0 & $0 \%$ & 0 & $0 \%$ \\
\hline
\end{tabular}

Sub-hypothesis on ethnicity. There were many commonalities found between ethnic groups and specific factors. With respect to American Indian/Native Americans $(n=1)$, the results of one participant cannot be used to generalize across the whole ethnic group. Therefore, that ethnic group was removed from comparisons. As mentioned before, the sample was predominately Caucasian/white $(83.9 \% ; n=344)$. Ethnic minorities made up $16.1 \%(n=66)$ of the sample which included $22(5.4 \%)$ Asian/Pacific Islander participants, 16 (3.9\%) African American/black participants, 14 (3.4\%) bi/multiracial participants, and 13(3.2\%) Latino/Hispanic participants, and 1 (.2\%) American Indian/Native American participant.

Asian/Pacific Islander students were the only ethnic group to cite the teaching/research assistantship ( $45.5 \%=M l ; n=10)$, alumni $(50 \%=M l ; n=11)$, and crime rate $(63.6 \%=\mathrm{Ml} ; \mathrm{n}=14)$ as generally important. Other ethnic groups agreed 
that these factors were generally not important. Approximately $50 \%$ of Asian participants were divided marking cost of living as moderately important $(50 \%=\mathrm{Ml} ; \mathrm{n}=11)$ and very important $(50 \%=\mathrm{Vl} ; \mathrm{n}=11)$. Seventy-seven percent $(n=17)$ of Asian participants felt the cost of education was a very important factor in their decision process.

African American/black students $(56.3 \%=\mathrm{Vl} ; \mathrm{n}=9)$ perceived the admission requirements as more important than other ethnic groups. While Latino students felt it was both moderately important $(38 \% ; n=5)$ and very important $(38 \% ; n=5)$, all other groups felt this factor was generally moderately important. Approximately $50 \%(n=8)$ of black students considered the length of the program, the marketability of the degree, and the quality of education factors to be very important. More than $60 \%$ of African Americans said status of accreditation $(n=10)$ and cost/affordability $(n=12)$ was very important.

$\mathrm{Bi} /$ multi-racial students perceived family as generally very important $(35.7 \%=\mathrm{Vl} ; \mathrm{n}=5)$ while all other ethnic groups perceived it to be less important. Weather was recognized as moderately important by $59.1 \%(n=13)$ of Asian participants and by $64.3 \%(n=9)$ of bi/multi-racial participants. The same amount of bi/multi-racial respondents ranked cost/affordability $(57.1 \% ; n=8)$, degree conferred $(57.1 \% ; n=8)$, and length of program $(57.1 \% ; n=8)$ as very important. Approximately $50 \%(n=7)$ of students believed a program's status of accreditation was a very important factor. 
Caucasian/white students, like African Americans, found the marketability of the degree to be very important $(52.3 \% ; n=180)$. In their decision process, degree conferred $(59.0 \%=\mathrm{VI} ; \mathrm{n}=203)$, quality of education $(57.0 \%=V I ; n=196)$, and status of accreditation $(54.7 \%=\mathrm{VI} ; \mathrm{n}=188)$ were all important factors. More than $50 \%$ of white students thought these factors were very important.

Though all ethnic groups cited the graduate assistantship and selfimprovement as generally very important, a higher percentage of Caucasians ranked the graduate assistantship $(85.5 \%=\mathrm{Vl} ; \mathrm{n}=294)$ as more important than self-improvement $(81.1 \%=\mathrm{VI} ; \mathrm{n}=279)$. As depicted below (in Table 6 on the next page), all ethnic minority groups perceived self-improvement $(89.2 \%=\mathrm{Vl} ; \mathrm{n}=58)$ as more important to them than the graduate assistant position $(75.4 \%=\mathrm{Vl}$; $\mathrm{n}=49$ ). Every group scored the diversity factors as generally not important and the motivational factors as very important, except the recognition factor. It was observed that $47 \%(\mathrm{VI} ; \mathrm{n}=31)$ of ethnic minority students felt recognition was more important compared to $37 \%(\mathrm{VI} ; \mathrm{n}=128)$ of non-minority students. Aside from the graduate assistantship and motivational factors, cost/affordability was the only other factor perceived as generally very important by each ethnic group; more than $50 \%$ of all groups shared this view. 
Table 6

Differences Between Ethnic Groups

\begin{tabular}{lccccc}
\hline Factors & $\begin{array}{c}\text { Asian/ } \\
\text { Pacific-Islander }\end{array}$ & $\begin{array}{c}\text { African } \\
\text { American/Black }\end{array}$ & $\begin{array}{c}\text { Bi/Multi- } \\
\text { racial }\end{array}$ & $\begin{array}{c}\text { Caucasian/ } \\
\text { White }\end{array}$ & $\begin{array}{c}\text { Latino/ } \\
\text { Hispanic }\end{array}$ \\
\hline $\begin{array}{l}\text { Graduate } \\
\text { Assistantship }\end{array}$ & $19(86.4 \%)$ & $10(62.5 \%)$ & $12(85.7 \%)$ & $294(85.5 \%)$ & $8(61.5 \%)$ \\
$\begin{array}{l}\text { Self- } \\
\text { Improvement }\end{array}$ & $20(90.9 \%)$ & $15(93.8 \%)$ & $13(92.9 \%)$ & $279(81.1 \%)$ & $10(76.9 \%)$ \\
\begin{tabular}{l} 
Recognition \\
\hline
\end{tabular} & $9(40.9 \%)$ & $7(43.8 \%)$ & $6(42.9 \%)$ & $128(37.2 \%)$ & $8(61.5 \%)$ \\
\hline
\end{tabular}

\section{Analysis of Qualitative Responses}

The last section of the survey included five open-ended questions. These questions were important because they allowed participants to elaborate on specific factors. Students were also able to expand on their personal experiences in selecting a graduate program. As the Likert-scale section had students rate factors, this section revealed that some factors were, in fact, barriers. Before analyzing the qualitative quotes from this section, they were read several times. All responses were color-coded for meaningful units and organized into themes. All the themes are supported with participants' quotes. Quotes consisting of one word or an incomplete thought were eliminated from consideration and those with minor grammatical errors have been corrected to facilitate reading. However, no editing was done that would change the context of the quotes. Pseudonyms were used to conceal the identity of particpants as 
required by the Institutional Review Board of San José State University to protect the anonymity of participants.

\section{Question 18}

The first question asked students to recall who was the most influential person in selecting a graduate program. Students elaborated on many factors already mentioned in the survey and even discussed barriers. After 324 quotes were organized, three major themes emerged: (1) self-motivation influences, (2) familial influences, and (3) non-familial influences.

Self-Motivation Influences. Several participants expressed being driven to pursue an advanced degree by self-improvement and aspirations. Of 324 responses, 117 students (36.1\%) stated that they were the most influential person in making their decision. Archie insisted he "wanted to make sure that [he] grew personally and professionally." Another student, Bridget described her decision process:

Although there were many people involved, I was the one who made the final decision. I believe that you have to be self-motivated to pursue continued education.

While some students acknowledged "other people's opinions," more students said, "I decided" or that the decision was, "solely made by [themselves]." Christian added that he "researched different programs" before 
deciding. Within the theme of self-motivation, students also alluded to location as an underlying factor. Examples included:

Dennis: Myself- I had to be happy with the decision I made since I would be moving away from family/friends.

Evette: It mostly came down to my own decision to stay close to home.

Fred: I am originally from San Jose and really wanted to move back to Northern California.

Through these quotes, location emerged as an important factor, but it also appeared to be a possible barrier. It was also noted that students who expressed a need to be close to home or were dissuaded by moving, selected graduate programs in-state. The theme of self-motivation influences reflected personal goals, achievements, professional development, and other intrinsic perspectives. Participants communicated that they were in control of their decision. In the next two themes, students explained how interpersonal relationships (familial and non-familial) affected their decision.

Familial Influences. Family served as a positive force to students as they explored graduate programs. This theme included quotes in which the mother, father, fiancé, spouse, boyfriend or girlfriend were found to be important influences. Family encouraged participants to apply to programs and assisted in 
the decision process "to decide which university would be best suited" for the students. The following quote shows a mother's impact on the student's choice:

My mom was sick all through my time at undergraduate school and became worse as I was about to graduate. She was definitely the reason why I came home for graduate school. The bad feeling in my gut came true and [she] passed while I was in graduate school. I'm glad I was home.

Again, the underlying theme of location is considered. For students who were married, engaged or in serious relationships, their significant other was the influential person. The importance of the relationship was clear in this quote: "Making my decision to continue my education was my decision, but where I chose to go to school was dependent on the relationship I was in at the time." For many, the selection of a graduate program revolved around family members. In the following theme, students described how the help of people unrelated to them affected their decision.

Non-familial Influences. Another recurring theme was non-familial influences. This category consisted of program directors, athletic training faculty, graduate assistants, alumni, mentors, bosses, and peers. Despite largely being ranked not important $(\mathrm{NI})$ and moderately important $(\mathrm{MI})$ in the quantitative section, students articulated their relationships with their program directors and 
how it affected their decision positively or negatively. Gigi, who had a bad relationship, gave the following report:

The person that most made me want to quit, and the one person that I will never recognize as contributing anything to my becoming an ATC is my ATEP director ... Worst program director ever.

As a result of the negative relationship, Gigi also said she would be continuing her education outside of athletic training to become a physician's assistant.

Most other students described program directors as "motivating" and "influential." After all, program directors were viewed as the gate keeper who decided if the student was accepted into the ATEP. Program directors continued to be instrumental to the student throughout the students' time in the program. Nineteen percent of students felt aided or encouraged to pursue an advanced degree and attributed these feelings to their program director. Herbert described how one program director was of assistance:

Sara Brown, the ATEP director at Boston University, was a very influential person who assisted me in making my decision to pursue a postprofessional athletic training educational program and degree.

A number of participants found Approved Clinical Instructors (ACls) and other athletic training faculty helpful as well. Ivy recalled, "My past ACls encouraged me to go to school out-of-state and put myself out of my comfort zone." In 
addition, ACls served as alumni connections further assisting the student with insight on the program of interest. These accounts indicated the influence of alumni connections:

Jeremy: Two former athletic trainers transferred from my undergraduate school where I looked for graduate school. I like seeing familiar faces.

Kimmy: My ACl from my undergrad ATEP program- worked as a graduate assistant where I now work.

Moreover, speaking to graduate assistants (at the program of interest) offered "real information and first-hand experience of what it was like to be a graduate assistant there." Many students spoke of mentors and bosses who were defined as people the student may know outside of the ATEP. Nonetheless, mentors and bosses were found to have an impact on Larry as follows:

My mentor from high school was a certified athletic trainer. I told him that I didn't think I could work as an athletic trainer forever, but still like orthopedics and medicine. He led me to the path of the Physician Assistant.

Michelle also commented on how informative her mentor was and how she eased her decision. She stated: 
A prior clinical instructor/mentor helped me in the decision making process. I found her to be very helpful as she is young and recently graduated and knows what it takes to get a job in collegiate athletics.

With regard to peers, some students pursued a master's degree "to keep up with [their] competition" and "to not be left behind." Though there was no peer pressure to continue education, there was rivalry among peers.

Though not a major theme, four students discussed their feelings and a sense of belonging. Through interviews and campus visits, students expressed how feelings of "fitting in" affected their decision. As an example, Noah, discussed how his interview established a sense of belonging:

Two of the professors I interviewed with were very welcoming and the exchange of ideas was amazing. I wasn't just another student; I was another researcher and friend.

A similar quote by Olivia echoed feelings of "fitting in" during her campus visit:

The people as a whole at each university that I interviewed with were the most influential. My on-site interviews allowed me to get a feel for whether or not I would fit in with the current graduate assistants, faculty, and staff. That is what my final decision was based on. 
Additionally, Prince insisted, "If I did not feel peace about the decision, I would have sought a different institution." In all, feelings of belonging gained through interviews, campus visits, and other interactions, were found to be important.

Although participants were specifically asked to state a person, six people cited other factors as being very influential. Just as the survey determined the importance of the graduate assistantship, students elaborated on why it was the deciding factor. Quinn remarked, "If I didn't receive the Grad Assistant position, I would not have attended graduate school." Russell implied, "I went to the school that offered me an assistantship." Only one student acknowledged "God" as their main influence saying, “...I have a good relationship and prayed throughout the entire decision making process."

While many people were found to be influential to the students, nonfamilial influences were reported by $51.9 \%$ (out of 324 respondents to this question). Some of the most influential non-familial influences included program directors (mentioned in 62 quotes) and other athletic training faculty (mentioned in 63 quotes). Thirty-six percent of participants cited themselves and intrinsic factors as motivation. Family was acknowledged by $21.3 \%$ to be an important factor. Aside from those, four students (1.2\%) thought personal fit influenced their decision and six students (1.9\%) considered resource related factors in their selection of graduate programs. 


\section{Question 19}

Professional Athletic Training Education Programs (ATEPs) assist students in many ways such as gaining clinical experience, providing general knowledge of athletic training, and developing professionally. When participants were asked, how their ATEP aided them, there were three main themes: (1) met student's needs, (2) exceeded student's needs, and (3) did not meet student's needs.

Met student's needs. In general, students' stated they were being helped in ways that were conducive to them pursing advanced degrees. Participants articulated how they were aided with letters of recommendation and phone calls to colleagues. Within the ATEP, the students also received guidance with cover letters, resumes, and interview preparation. Some students felt that this, in addition to their strong foundation of knowledge, "prepared" them for graduate school. Sierra shared how the ATEP was of assistance:

My undergraduate program helped me continue to have the desire to keep learning and further my knowledge. They also emphasized pursuing your goals to the best of your ability and not settling for less than what you truly want.

Exceeded student's needs. In this theme, participants wrote more than three forms of aid given by their ATEP. Unlike students in the previous theme that felt "prepared," these students felt "ahead" of peers. In addition to being 
prepared for the Board of Certification Exam, students were prepared for the Graduate Records Examination and exposed to research. Travis said, "It helped me improve academically, personally, and professionally, which aided me in my choice..." ATEPs that exceeded students' needs showed students "different avenues" to graduate education that went beyond alumni connections and graduate assistantships. Ursula told how the ATEP exceeded her needs:

High expectations and emphasizing the importance of wanting to make yourself a better athletic trainer or professional; classroom lectures focused on our options and the process of moving forward in our education; personal meetings with undergraduate and graduate program director on personal goals and mentoring from them.

Did not meet student's need. A few students (17\%) argued their ATEP did not meet their needs to continue their education. These participants claimed ATEPs "did very little" or "not a whole lot." Although the ATEP may have advocated graduate school, students insisted that they were given "no formal help from [them]." Vince explained how the lack of assistance affected his decision to pursue an advanced degree:

Not at all, I didn't feel encouraged to pursue my masters while in undergrad; hence, I waited 10 years to pursue my master's after becoming certified. 
Typically, these students were frustrated when their program was unable to assist them with the knowledge and instruction needed to achieve their goals.

Out of 311 responses, $57 \%$ of students believed the ATEP met their needs, $16 \%$ of students believed the ATEP exceeded their needs, and $5 \%$ of students said it did not meet their needs. Accounting for the remaining $20 \%$ was difficult because many of these students had not attended ATEPs. Characteristically, these students attended or were attending EntryLevel Master's Athletic Training Program (ELMs). Therefore, they were unable to answer question 19. This accounted for many of the "n/a" responses. However, for participants that had a bachelor's degree in athletic training, and pursued an advance degree in another field, determining how, if at all, their ATEP aided them was challenging. Wendy, who completed her master's in sport management, said:

My undergraduate classes in administration and organization of athletic training helped a great deal with my graduate classes in sport law, sport marketing, organization and administration of sport, etc. Also, my sport and exercise psychology classes that I took attaining a minor in undergraduate work helped me in my graduate sport psychology class. My master's degree was in sport management so not many of my undergraduate classes applied to my graduate classes. 
In this instance, Wendy found that much of her athletic training education did not prepare her for sport management. Students, who pursued non-athletic training master's programs, may not have been completely prepared for their particular field of study.

\section{Question 20}

In this question, participants were asked what information or knowledge was passed down to them. Generally speaking, students reported being encouraged to pursue a master's degree. The responses showed student's were getting information in class, over the internet, or researching on their own. There were several small themes with less than 10 people. These themes varied with students disclosing knowledge passed down regarding the Continuing Education Units, the benefits of a master's degree, the experiences of faculty, and the value of higher education. The most common themes in this question were as follows: personal marketability, graduate assistantship, and obligation.

Personal Marketability. As determined in the survey, more than $50 \%$ (out of 246 responses total) of students considered marketability important. Many participants received knowledge of this kind from approved clinical instructors, program directors, and advisors. Being marketable implied one was invaluable, sought after, and expanded career opportunities. With a bachelor's degree, Xavier said opportunities for work were "limited to high school and freelance work." But with a master's degree, students anticipated more doors 
opening. The perception was that, all or "most career opportunities prefer candidates with an advanced degree." Therefore, the marketability of a master's degree was highly regarded by students.

Graduate Assistantship. Based on the quantitative responses, the most influential factor was the graduate assistantship. Twenty-four participants (out of 246 that answered this question) recalled being told information specifically relating to a graduate assistantship. Yasmin shared this:

All of my undergraduate ATEP professors gave me their opinions on each of the schools I was interested in. They often told me to go where I could get a good clinical experience without enduring too much of a financial burden.

Based on the qualitative responses, the clinical experience was advocated more than the academic values and the research aspect of graduate programs. However, two students talked about theses and how they were informed by clinical instructors to "find a program with a non thesis option." Just one student felt "inclined" to write a thesis as a part of graduate school.

In the student's mind, a graduate assistant position was the ultimate way to cut costs. Zeus said he would attend graduate school, "but only if I get a graduate assistantship along with it to help with cost." Before graduating, the importance of selecting a graduate assistantship was instilled in students by the athletic training faculty. 
Obligation. Though a bachelor's degree satisfies the educational requirements for athletic trainers and entry into the profession, students felt they needed more than this. Before practicing, an athletic trainer must pass a Board of Certification Exam and obtain licensure, if required in their state's practice acts. Yet, $6.5 \%$ of athletic training students (16 of 246 that responded) believed, "It is hard to find a job without a master's in today's world." Certain careers in athletic training may warrant higher education. For instance, a professor of athletic training must possess one degree beyond the student's highest level of education. Addy argues, "A terminal degree is necessary for curriculum instruction in ATEP." A few students insisted that employers require a master's degree. "Searching for new jobs was difficult when suddenly most jobs required a master's degree," said Ben. Another student interested in working with collegiate athletics shared:

My undergrad professors said that getting my masters now will put me ahead of the game, because one day every athletic trainer will need their masters to continue practicing. Also, to get into a university setting, they said getting a master's is almost required.

In physical therapy, the educational requirement recently changed from a master's degree to a doctoral degree. Even though athletic training is closely related, there is no news of a similar movement in the future of athletic 
training. Nevertheless, some students still feel a professional obligation to continue their education.

Among the various forms of encouragement, seven participants were instructed not to pursue an advanced degree in athletic training. This small group was unique in their responses, but interesting. Although generally encouraged to continue their education, they were specifically advised not to attended athletic training programs for graduate school. It was thought that, "Further knowledge outside of athletic training is helpful [...] when you have an undergraduate degree in [athletic training]." This advice was given by many athletic trainers. In addition, students were persuaded to seek advanced degrees in other fields to become "more marketable." Crystal mentioned:

It is really important these days to have that experience while you get your master's to get a good job once you have graduated from there. They said that it wasn't essential that I get a master's in athletic training, so if I were to get it in another area, that might make me more marketable. This advice was given to me by all of the athletic trainers at Central as well as some of the alumni that I was still friends with who had gone through the program.

Other participants felt a master's degree in any subject would suffice. In particular, Darius recalls, "It did not matter what master's degree I obtained...Much learning and personal growth will be obtained through my sport 
assignment." Again, a strong emphasis was placed on the related practical experience or graduate assistantship. Despite the consequences of what information and knowledge was passed down, it appears that many students are being encouraged to "never stop learning."

\section{Question 21}

In question 21, participants were asked to specify their career objective. The purpose of this question was to determine how many students sought careers in athletic training regardless of their chosen master's degree program. Two main themes stood out: athletic training career paths, and nonathletic training career paths.

Athletic Training Career Paths. Based on 340 responses (to this question), $90.6 \%$ ( $n=308)$ of the participants planned on staying in the profession. Students reported their desire to work at many levels of athletic training from youth to professional sports. The work settings varied and included, but were not limited to, working in hospitals, clinics, performing arts centers, and the military. Eddie stated that his desire was, "Ultimately, working in a corporate setting improving outreach and rehabilitation-related programs for the greater benefit of athletic trainers and athletes alike." Among the 308 respondents choosing careers in athletic training, $22.1 \%(n=68)$ of the respondents were interested in the field of education. Students discussed wanting to become professors and program directors, but still wanted to work clinically. 
Non-Athletic Training Career Paths. Eleven percent $(n=39)$ of students (out the 340 responses total) stated they would pursue careers outside of athletic training. While most students expressed wanting to be a physician's assistant or physical therapist, others chose to work in related fields such as selling medical devices, owning their own clinic, or starting a chain of performance facilities. Flora, who achieved a Master of Arts in Physical Education, plans to be a physical education teacher at an elementary school.

According to this question, at least eight students (2.4\%) were still contemplating potential career paths. A few students gave answers too broad to define like, "To have a great career and happy family wherever that may take me." Altogether, only a small amount $(11.5 \% ; n=39)$ of respondents indicated they would settle for a career in another field.

\section{Question 22}

In the last question, students were asked whether or not they would continue their education for a doctoral degree. Of 346 responses, three themes emerged: (1) No, (2) Yes, and (3) Maybe/Undecided.

No. Fifty percent $(n=175)$ of students were not going to pursue a doctoral degree. Some students explained why they chose to stop at a master's degree and even discussed specific future plans. Within this major theme, there were five underlying themes: (1) Redundancy, (2) Burnout, (3) Money, (4) Eager to Start Career, and (5) Additional Certifications. Students who wished to work 
exclusively as clinical athletic trainers felt there was "no need" for an advanced degree. Geoffrey asserted how redundant the degree was:

No, there is no need to the practical athletic trainer to pursue a doctoral degree. It is important to those who want to get into education. The new practical doctoral program, I believe, will do more damage than good to the profession and is an unnecessary degree. It is just as useless as having the DPT [Clinical Doctorate of Physical Therapy] or calling chiropractors doctors.

Another minor theme presented was burnout. Typically students claimed to be fed up with school, sick of homework, or too mentally exhausted to continue their education:

Hallie: My current plan is to not pursue a doctoral degree, because I feel like I need a break from structured education and would like to focus on my clinical skills.

Ike: I am feeling a little burned out from school, so at this point in time, I do not find myself with the right mind set to pursue a doctoral degree.

Jan: No. l'm totally burned out on school and looking to gain more experience marrying my MBA and ATC/L.

Money-related issues were also frequently cited. Some students were burdened by debt or needing to make money first. Without adequate funding, these 
students were not interested in going back to school. This underlying theme was supported by Kelvin, who communicated about his financial status:

I had thoughts, but decided to work a couple years in the field first. I needed to make some money, and a doctoral degree would have cost too much and placed me further in debt. Plus, I don't think a PhD would advance me further up the pay scale working on the clinical side. If I ever have the desire to enter academia or teach, then I might reconsider a $\mathrm{PhD}$.

Although no other students made reference to the pay of doctoral-educated athletic trainers, students were too burdened by debt to consider further education. Moreover, the deferred student loans and unsettled debt made students eager to enter the workforce immediately.

The last underlying theme was students seeking other certifications instead of a doctoral degree. For example, Louise commented, "Most likely not, I wish to use multiple certifications to bridge the gaps between." Though it is unclear what Louise means by "bridge the gaps," it is common for athletic trainers to hold other certifications. Additional certifications may include Certified Strength and Conditioning Specialist (CSCS), Corrective Exercise Specialist (CES), Performance Enhancement Specialist (PES), Physical Therapy Aide (PTA), and many more. 
Yes. Twenty-two percent $(n=75)$ of the qualitative responses to this question indicated an interest in pursuing a doctoral degree. In general, these students said they enjoyed research, valued education, wanted to remain competitive, were highly motivated, and believed it would increase their marketability. The following participants gave reasons for their decision to pursue a doctoral degree:

Micah: Yes, it will allow me more opportunities to work on research. The increase in salary is also a big draw. Unless athletic trainers start getting paid what we are worth, there is always the possibility that I will leave the profession so I can support a family in the future.

Noelle: I will. The new terminal degree for our profession is surely becoming a doctoral degree. Obtaining one will help set the bar for improved education for all athletic trainers across the board.

Owen: Yes...Education is very important, but clinical experience and knowledge is invaluable and cannot be "taught."

For highly motivated individuals, this degree was "the pinnacle of education endeavors," one respondent declared. Some students felt the doctoral degree was necessary for attaining career goals of being a program director or professor. Penny insisted on "becoming a college professor," while Quincy said it was "to be able to live up to [his] potential as an educator." Despite only one 
program in the nation offering a Clinical Doctorate of Athletic Training, an interested Rosalind said:

I plan to pursue a doctoral degree 2-3 years after I complete my master's degree...I also want to wait since there is currently only one doctor of athletic training program in the country and that degree is of interest to me, but I do not know much about it because it is so new.

There were also students who detailed their specific plans for an advanced degree. Seven students spoke of attending Doctor of Physical Therapy (DPT) programs. One female claimed:

I plan on becoming a DPT because having the combo of degrees/credentials is imperative to higher level/more desirable positions...and, in my opinion, I need it as a female trying to get to those higher positions.

A few students chose to continue their education by achieving a second master's degree. For example, Swaylan proposed, "I will pursue my second master's in administration and supervision." Some students felt that, "to be more of a valuable asset to the sports medicine field" becoming a physician's assistant or chiropractor would accomplish this. Terry added: 
I will pursue a doctorate in law. I have been around law for years and have been intrigued by the laws and regulations of [BOCATCs]. I would like to advocate for the profession and defend against malpractice.

Even with plans to enter other fields of study, Terry and other students still plan to contribute to the profession, just from a different angle.

Maybe/Undecided. Twenty-eight percent (96 of 346) of respondents indicated that they were unsure if they would pursue a doctoral degree. Approximately 72 participants stating "maybe" or "possibly" expressed a desire to teach, but needing time off before embarking on a doctoral program. Also, these students wished to gain more experience in the field before pursuing a doctoral degree in the future. Ulysses communicated:

I have considered the option and would like to think about doing that further down the road. I feel that doctoral degrees have a primary purpose to research and enter into academic roles. I would love to teach, but not at the expense of losing my clinical role in the profession.

Unlike Ulysses, some participants had not yet considered pursuing another advanced degree. Twenty-four respondents said they were unsure, currently, if they would pursue a doctoral degree. Participants articulated: 
Valerie: Currently, I am working on a thesis, so if I do decide to pursue a doctoral degree I have some experience with research. However, I am undecided as to whether or not I will pursue a doctoral degree.

Wayne: I am not sure at this moment, if I will be pursuing a doctoral degree in Athletic Training. It is not something that I have given much thought to.

In general, it was found that these respondents tended to be younger, newly accepted students that had not yet given much thought to more education.

\section{Summary}

The participants in this study were largely Caucasian/white (83.9\%; $n=344)$ females $(66.3 \% ; n=272)$ under the age of $27(90.7 \% ; n=372)$. Overall, the students reported the graduate assistantship $(83.9 \%=\mathrm{VI} ; \mathrm{n}=344)$ to be the most influential factor. The factors within the motivational category were combined and collectively called motivational factors which represented the second most important factors. The degree conferred $(56.8 \%=\mathrm{VI} ; \mathrm{n}=233)$ was found to be the third most influential factor followed by the perceived quality of education $(56.3 \%=\mathrm{VI} ; \mathrm{n}=231)$. The cost of education/affordability $(53.7 \%=\mathrm{VI}$; $\mathrm{n}=220)$ factor, tied with status of accreditation $(53.7 \%=\mathrm{Vl} ; \mathrm{n}=220)$ as the fifth most important factor. Marketability of the degree $(51.0 \%=\mathrm{Vl} ; \mathrm{n}=209)$ was the sixth factor and the last one to receive more than $50 \%$ of rankings as very important. 
According to gender, females found distance from home, size of city/town, weather, and marketability of the degree to be much more important than males. Also, males considered the program director not important, while females said the program director was generally moderately important in their decision process.

With regard to age, the youngest group (defined as those younger than 24 years) found the program director, alumni, and size of enrollment more important than other age groups. The middle age group (defined as those between 24 and 27 year) was divided on the prestige of athletics factor; half of students thought it was not important and the other half thought it was moderately important. The older group (defined as those older than 27years) generally indicated the prestige of athletics was not important compared to the younger groups that generally found it moderately important. Additionally, older participants considered weather, admission requirements, and the length of the program more important than the younger participants. All groups varied in rankings of the importance of crime rate. While older students generally perceived crime rate as not important and moderately important, the middle age group perceived it as not important. The youngest age group perceived it as moderately important.

Several trends appeared among the various ethnic groups. Although the graduate assistantship was the top rated factor, higher percentages of minority 
students ranked self-improvement as more important. Asian students stood out as the only ethnic group that indicated the teaching/research assistantship factor, alumni factor, and crime rate factor as important; all other groups indicated they were not important. To bi/multi-racial students, family was a more important factor than any other group. Distance from home and location of program were key factors for many Latino/Hispanic students. Meanwhile, African American/black students generally thought admission requirements were very important. Caucasian/white students were generally more concerned with the marketability of the degree than minority groups. In general, the motivational category received the highest percentages of very important rankings from all groups, except regarding recognition. However, ethnic minorities viewed recognition as more important than non-minority students. Generally, all ethnic groups rated diversity factors as not important in their selection of a graduate program.

As for the qualitative section, the program directors and athletic training faculty were the most important people to the student. Students $(57.6 \% ; 179$ out of 311 responses total) felt they were well-prepared for graduate school and few $(5.5 \% ; 17$ out of 311$)$ reported not being helped to continue their education. Despite ATEPs encouraging students in a variety of ways, there are still some students being advised not to continue their education in athletic training. Also, few students plan to pursue a doctoral degree as they reported being too burnedout, too burdened by debt, or they just did not see the need. Instead students 
are more likely to start working or obtain additional certifications after their master's degree. 


\section{Chapter 5}

\section{Conclusion}

Students are able to pursue several avenues for graduate education in athletic training. The variables influencing student selection are a critical area of inquiry to athletic training educators, though no research known to the author has been conducted on this issue. In this study, data regarding the factors influencing students' choice of graduate program were collected. The purpose of this study was to explore the factors influencing student choice and to determine the most influential factors. In addition, this study sought to examine the differences among the factors as they related to gender, age, and ethnicity. The exploratory and descriptive nature of the study provided a glimpse into the decision process from the student perspective. While most of the previous research studies from other professions were either qualitative or quantitative, this study incorporated both methods via a web-based survey. Chapter 5 begins with a brief review of the procedures in which the study was conducted followed by: Summary, Discussion, Conclusions, and Future Implications.

\section{Summary}

The results of this study did not support the hypothesis that there was no factor, singled out, as the most influential. Although many factors were determined to be very important, the graduate assistantship factor emerged as the most important and influential factor as $83.9 \%(\mathrm{Vl} ; \mathrm{n}=344)$ of respondents 
chose this option as most influential. In the qualitative responses, it was found that program directors and other athletic training faculty encouraged students to attend graduate school and placed an emphasis on students acquiring a graduate assistant position. Except for recognition (46.8\%=Ml; $n=192)$, all factors in the motivational category were perceived to be very important. The motivational factors (excluding the recognition factor) represented the second most important factor to $73.4 \%(\mathrm{Vl} ; \mathrm{n}=301)$ of participants. When asked who the most influential person was in their decision-making process, $36.1 \%(n=117)$ of respondents cited self-motivation as the main influence.

The third most important factor was the degree conferred $(56.8 \%=\mathrm{Vl}$; $\mathrm{n}=233$ ); six students reported being told not pursue master's programs that would confer a master's degree in athletic training. Though students never spoke of the quality of their education in the qualitative responses, $56.3 \%(\mathrm{VI} ; \mathrm{n}=231)$ of students considered the perceived quality of education to be the fourth most important factor. Cost/affordability tied with status of accreditation for fifth place receiving $53.7 \%(n=220)$ of rankings as very important. The marketability of the degree $(51.0 \%=\mathrm{VI} ; \mathrm{n}=209)$ was the last factor with more than $50 \%$ of respondents identifying it as very important. In qualitative question $20,10 \%$ (26 of 246 responses total) of respondents reported being encouraged to continue their education to be perceived as marketable. 
Specific factors were found to have an effect on gender, age, and ethnicity. There were $272(66.3 \%)$ female and 138 (33.7\%) male participants. Males and females differed on the importance of geography, program directors, and marketability of the degree. Male students generally perceived the distance of the program from home $(42.8 \%=\mathrm{Nl} ; \mathrm{n}=59)$, size of the city/town $(51.4 \%=\mathrm{NI}$; $\mathrm{n}=71)$, and weather conditions $(50.0 \%=\mathrm{NI} ; \mathrm{n}=69)$ as not important. Females generally perceived the distance of the program from home $(42.0 \%=M l ; n=114)$, size of the city/town $(47.4 \%=\mathrm{MI} ; \mathrm{n}=129)$, and weather conditions $(47.4 \%=\mathrm{Ml}$; $n=129)$ as moderately important. More females $(42.3 \% ; n=115)$ indicated the ATEP program director was generally moderately important in their decision, but males were split; $36.2 \%(n=50)$ felt the program director was not important, while the same amount thought the program director was moderately important. Also, females $(54 \%=V l ; n=147)$ cared more about the marketability of the degree than did males $(47.8 \%=\mathrm{Ml} ; \mathrm{n}=66)$.

The participants were split into three age groups: those less than 24 years (44.1\%; $n=181)$, those between $24-27$ years $(46.6 \% ; n=191)$, and those older than 27 years $(9.3 \% ; n=38)$. Looking at the effects on age, the two younger groups seemed to agree on most factors. Older students perceived the location of the program to be generally very important $(52.6 \% ; n=20)$; both of the younger groups thought it was generally moderately important. The oldest respondents $(52.6 \% ; n=20)$ attended graduate schools in-state and ranked the location of the program as very important $(52.6 \% ; n=20)$; therefore, older students were more 
likely to select graduate programs in-state. Additionally, weather $(44.7 \%=\mathrm{Ml}$; $\mathrm{n}=17)$, admission requirements $(44.7 \%=\mathrm{VI} ; \mathrm{n}=17)$, and the length of the program $(50.0 \%=\mathrm{Vl} ; \mathrm{n}=19)$ were all factors generally considered important to older students.

The youngest respondents found many factors important that the other groups did not. The following factors were only generally important to the youngest age group: ATEP program director $(52.5 \%=M I ; n=95)$, size of the city/town (49.7\%=Ml; $\mathrm{n}=90)$, alumni (45.3\%=Ml; $\mathrm{n}=82)$, and size of enrollment (48.1\%=Ml; $n=87$ ). Distance of ATEP from home was moderately important to $80(44.2 \%)$ young respondents and $80(41.9 \%)$ middle age respondents. Of the middle age group, $47.1 \%(n=90)$ indicated that the crime rate was generally not an important factor while the other groups generally indicated it was moderately important in their decision making process. The middle age respondents were also divided on the importance of the prestige of the institution's athletic teams with $37 \%$ of ratings indicating not important $(n=71)$ and moderately important $(n=72)$. Older students $(42.1 \%=\mathrm{Nl} ; \mathrm{n}=16)$ were less likely to consider the prestige of athletics teams important when selecting a graduate program, but $49.2 \%(n=89)$ of the youngest students found it moderately important.

Responses varied among specific ethnic groups in this study. The respondents were largely Caucasian/white $(83.9 \% ; n=344)$. The remaining $16.1 \%(n=66)$ of participants included the following ethnic minorities: $22(5.4 \%)$ 
Asian/Pacific Islanders, 16 (3.9\%) African American/blacks, 14 (3.4\%) bi/multiracial, and 13(3.2\%) Latino/Hispanics. Although the graduate assistantship factor was the most important factor, higher percentages of minority students identified self-improvement $(89.2 \%=\mathrm{Vl} ; \mathrm{n}=58)$ as more important than the graduate assistant position $(75.4 \%=\mathrm{Vl} ; \mathrm{n}=49)$. In contrast, a higher percentage of Caucasians perceived the graduate assistantship $(85.5 \%=\mathrm{VI} ; \mathrm{n}=294)$ as more important than self-improvement $(81.1 \%=\mathrm{Vl} ; \mathrm{n}=279)$. All ethnic groups ranked the diversity factors as generally not important and the motivational factors as generally very important. However, minority students considered recognition $(47 \%=\mathrm{Vl} ; \mathrm{n}=31)$ more important compared to non-minority students $(37.2 \%=\mathrm{VI}$; $n=128)$.

Even though all participants did not submit responses for open-ended questions, the feedback was rich and provided a better understanding of how certain factors affected the students. The first question asked participants who was the most influential person in their decision; out of 324 responses submitted, three themes emerged: (1) self-motivation influences (36.1\%; $n=117)$, (2) familial influences (21.3\%; $n=69)$, and (3) non-familial influences $(51.9 \%, n=168)$. Nonfamilial influences had the greatest impact on students according to the responses. Despite the program director factor being ranked generally moderately important in the survey, more students cited the program director and athletic training faculty as being more influential than any other person. 
The next two questions pertained to the students' ATEP. Therefore, if the student did not attend an ATEP, as was the case with many students at ELMs, they were unable to answer. In these questions, the participants were asked how their program aided them (311 responses were submitted) and what knowledge was passed down (246 responses were submitted). Most students (57.6\%; 179 of 311 ) felt "prepared" for graduate school; therefore, the ATEP had met their needs. Students that felt "ahead" of peers or listed multiple ways in which the ATEP assisted them were categorized in the theme, "exceeded students' needs." Only 5.5\% (17 of 311) students indicated the ATEP did not meet their needs. Also, if the student pursued a non-athletic training graduate program (i.e. sport management), it was difficult to determine if their ATEP was of help. In general, students reported that their ATEP encouraged them to continue their education, though sometimes not in athletic training $(n=6)$. The majority of the information passed down to students pertained to the marketability of the degree $(10.6 \% ; 26$ of 246$)$ and to the graduate assistantship $(9.8 \% ; 24$ of 246).

This research also yielded information regarding the career objectives of students pursuing a master's degree. Three hundred-forty participants submitted responses. It was found that $90.3 \%$ (308 of 340 ) of the respondents planned to seek a career in the field. Students generally indicated a desire to work in a collegiate, high school, or professional setting. Of the 308 students that stated they would remain in the field, $22.1 \%(n=68)$ are planning for careers in the field 
of athletic training education. Only $11.5 \%$ (39 of 340 ) students stated they planned to pursue non-athletic training career paths (e.g. physician's assistant). Eight students (2.4\%) were undecided.

The last question revealed future educational plans of 340 respondents. Half of the respondents $(50.6 \% ; n=175)$ stated that they would not be pursue a doctoral degree. Reasons for this included: redundancy of the degree, burnedout from master's program, money-related issues, being eager to start one's career, or attaining other certifications instead. Twenty percent $(n=72)$ of participants said they might purse a doctoral degree and $6.9 \%(n=24)$ were undecided. Among the $21.7 \%(n=75)$ of participants that claimed they would continue their education, 56 students said yes; 12 students said yes, but in another field; and 7 students said yes, in favor of a doctor of physical therapy.

\section{Discussion}

Several factors found to be generally important to students in this research were also found in earlier research from other professions. Johanson (2004) compared factors influencing master of physical therapy students versus doctor of physical therapy students and found several differences. The master's students in her study ranked the length of the program and marketability of the degree as important. Students in the present study agreed. However, class size and matriculation date were not found to be important to graduate athletic training students, but were important to master of physical therapy students. 
Doctoral students felt the degree, curriculum, reputation of the faculty, and reputation of the program were more important. While this study did not have a factor examining curriculum, the faculty and program prestige were comparable to the faculty and program reputation. Students in the current investigation agreed with Johanson's (2004) participants on the importance of the degree awarded; the degree conferred was the third most important factor to respondents in the current research.

Wilcox et al. (2005) and Johanson (2007) investigated factors influencing minority students' choice of physical therapy programs. Wilcox and associates (2005) stated minority students ranked cost, ethnic, cultural, and gender considerations, and faculty of the program higher than non-minority students. Although the cost was perceived as more important to minority students in the current research, other findings did not correlate with the research of Wilcox (2005). A surprising finding in this investigation indicated that minority students did not consider diversity factors relating to ethnicity, cultural, and gender considerations to be particularly important. In fact, these factors received the highest percentages in the survey for "not important."

Johanson (2007) studied the differences between ethnic groups and concluded that minority students found the program rank, financial aid, number of prerequisites, and positive interactions to be most important. Similar to Johanson's number of prerequisites factor, the admission requirements factor in 
the current research was generally found to be important among African American/black and Latino/Hispanic students. Johanson's study also compared gender where the reputation of faculty was found to be more important to males while the location, cost, financial aid, prerequisites, and positive interactions were more important to females. In the current investigation, females found locationrelated factors to be more important than males, unlike Johanson's (2007) research.

Previous research on factors influencing social work students added that no significant differences in gender were found between males and females (Kindle \& Colby, 2008). Contrary to that finding, the current research found that females perceived the program director, distance from home, size of the city/town, weather, and marketability of the degree as more important than males. Kindle and Colby (2008) also noted that those who moved tended to be younger than those who did not move. This finding was supported in the current research where older students considered the program's location to be generally very important and attended graduate programs in-state, whereas younger students did not feel the location was as important and many attended graduate programs out-of-state.

In nursing, Meadus (2000) illustrated how the perceived status as a female occupation deterred male students. Similarly, the literature review in the current research exposed a long history of athletic trainers continuing their 
education in physical therapy so they could be more marketable. In turn, the tradition of athletic trainers continuing their education in physical therapy and other field has deterred some athletic training students from selecting athletic training programs at the graduate level. As explained in the qualitative section of this research, six students were encouraged to pursue another field of study to make themselves more marketable. Moreover, seven students expressed specific plans to continue their education in physical therapy.

Another nursing study (Kippenbrock, 1990) found differences on the factors that influenced males. Kippenbrock (1990) advocated more male faculty in nursing programs because he determined that males applied and enrolled in programs with more male faculty. Ninety-three percent $(n=129)$ of males in the current investigation viewed faculty of the same gender as not important; therefore increasing the number of male faculty in graduate athletic training programs would not lead to a rise in males students in athletic training.

Research on physiotherapists found some similar findings influencing athletic trainers in the current research. Glover et al. (2008) found that the desire "to develop" was the most influential intrinsic motivator among physiotherapy students. Similarly, self-improvement, the desire for knowledge, the ability to contribute to the profession, and aspiration, were all intrinsic motivators found to influence students in the current research. 
Kanji and colleagues (2010) conducted research that concurred with the findings of the current study. Kanji et al. (2010) highlighted the factors important to dental hygiene students: career opportunities, personal development/desire for knowledge, status/recognition, access to graduate education, and third person influences. Excluding status/recognition, all other factors were perceived by athletic training students as being generally very important. Access to graduate education was not listed in the current survey, nor was it mentioned by students in the qualitative responses, but career opportunities, personal development/desire for knowledge, and third person influences (i.e. family and non-family) were.

Hertlein and Lambert-Shute (2007) found that funding was important, but that it was not the most important factor to students; "personal fit" was the number one factor among master's and doctoral students in marriage and family therapy graduate programs. In the current study, "personal fit" emerged as a theme when the students were asked who was the most influential person in their decision process; this theme referred to a sense of belonging and feelings of "fitting in." In comparison, Hertlein and Lambert-Shute defined personal fit as cultural diversity, social interaction, location, student culture, and similarity of religious philosophies (2007). Excluding location, all those factors (i.e. cultural diversity, social interaction, student culture, and similarity of religious philosophies) were listed in the diversity category of the survey and found to be generally not important to graduate athletic training students. Hertlein and 
Lambert-Shute did examine the effect of graduate assistantships, referred to as the funding factor, in the selection of graduate marriage and family therapy programs. Along with clinical work, this factor was the second most important to their students. In the current study, the funding factor (being the graduate assistantship) was found to be the most important factor to athletic training students. There were also similar findings regarding the teaching and research factors between these two studies. In both studies, it was found that few students perceived either factors to be important.

\section{Conclusions}

This study found that students perceive a graduate assistantship, by far, to be the most influential factor when selecting a graduate program. There were also differences in the factors found important among gender, age, and ethnicity. Females showed more interest in the geography-related factors. Also, the marketability of the degree and the ATEP program director were more important to women. In regard to age, older students indicated location was more important and were more likely to live in-state than younger students. On the contrary, younger students did not view location as important as older students and were more likely to move out-of-state.

Among ethnic groups, there were differences in the factors perceived to be important. Asian students found the teaching/research assistantship, alumni connections, and crime to be important while other ethnic groups did not. 
$\mathrm{Bi} /$ multi-racial students stood out as the only group to consider family very important as an influential factor in their choice of graduate programs. Black and Latino students thought admission requirements were more important than others groups. While ethnic minority groups agreed that self-improvement was more important than the graduate assistantship, white students found the graduate assistant position to be the most important factor overall. In addition, it was found that minority students believed the recognition that came with achieving a master's degree was more important to them than to white students'.

Regardless of demographic characteristics, all students strongly considered factors in the motivational category (i.e., self-improvement, aspiration, desire for knowledge, ability to contribute to profession) to be generally very important. Diversity factors, those pertaining to cultural and ethnic considerations, were not found to be important to any of the sub-groups investigated. Overall, the participants in this study received a great deal of information relating to graduate assistant positions and believe such assistance was very important to attend graduate school. From the qualitative responses, it can also be concluded that, despite students pursuing various fields of study for their master's degree, many students are choosing to stay in the profession. Nevertheless, many students have been deterred from pursuing master's degrees in athletic training. 


\section{Future Implications}

The findings of this study have implications for athletic training educators in ATEPs and graduate programs everywhere. These finding suggest that, in preparation for graduate school, students need to be shown more options and different avenues to pursue a master's degree, rather than only being given graduate assistantship information by athletic training faculty. There is also evidence that suggest athletic training staff is informing students not to attend graduate programs in athletic training; therefore, further research is warranted to explore that phenomenon, why it is occurring, and if is it viable advice. In addition to in-class preparation for graduate school, students generally appreciated and benefited from one-on-one meetings with their program directors.

Graduate programs may utilize the findings in this study to alter marketing and recruitment strategies. While publicizing graduate assistant positions, graduate programs should highlight the degree conferred, quality of the education, cost of attendance, and the marketability of the degree. All these factors were found to be generally very important in the students' decision. Also, $53.3 \%$ (220 of 410 ) students indicated the importance a status of accreditation (though not limited to NATA-accreditation or CAATE-accreditation); therefore, it may be recommended that unaccredited graduate programs seek accreditation. 
Although this research is the first of its kind in athletic training known to the author, more research on the factors influencing student selection of graduate programs is necessary. Future research should take into consideration the number of graduate athletic training programs to which students applied and were accepted. This study illustrated the college choice among hundreds of students to be a complex, multifaceted decision; therefore, further research from a qualitative perspective may better explore this phenomenon. With the array of graduate opportunities available, future research should seek to understand the factors influencing students in different graduate programs (e.g., unaccredited programs v. accredited programs; athletic training programs v. non-athletic training programs) and students who do not attend graduate school. 


\section{References}

Abernethy, E. H., Jr. (1996). Factors influencing student selection of sport management graduate programs: Marketing implications (doctoral dissertation, Ohio University). Available from ProQuest Dissertations and Theses database. (UMI No. 9713154)

AMA endorses athletic training as allied health profession. (1990). NATA News, 4.

Commission on Accreditation of Athletic Training Education. (2011) List of Accredited Programs. Retrieved January 1, 2011, from http://www.caate.net/imis15/CAATE/Home/CAATE/Default.aspx?hkey=b3 $\underline{\text { 4a00e6-3a05-4c07-9997-0cb0ae693d32 }}$

Delforge, G. D., \& Behnke, R. S. (1999). The history and evolution of athletic training education in the United States. Journal of Athletic Training, 34(1), 53-61.

Dodge, T. M., Mitchell, M. F., \& Mensch, J. M. (2009). Student retention in athletic training. Journal of Athletic Training, 44(2), 197-207.

Glover, P., Bulley, C., \& Howden, S. (2008). Influences on physiotherapists when deciding to study at masters level: An exploratory study. Advances in

Physiotherapy, 10(1), 15-20.

Henry, K. J., Van Lunen, B. L., Udermann, B., \& Oñate J. A. (2009). Curricular satisfaction levels of National Athletic Trainers' Association-accredited post professional athletic training graduates. Journal of Athletic Training, 44(4), 391-399.

Hertlein, K. M., \& Lambert-Shute, J. (2007). Factors influencing student selection of marriage and family therapy graduate programs. Journal of Marital and Family Therapy, 33(1), 18-34.

Ingersoll, C. A., \& Gieck, J. H. (2003, June). Why certified students should enroll in accredited graduate programs. Presented at National Athletic Trainers' Association Convention, St. Louis, MO. Retrieved January 1, 2011, from, http://www.nata.org/education/educational-programs/post-professionaleducation-programs 
Ingersoll, C. A., \& Gieck, J. H. (2005, January). Issues and outcomes in graduate education. Presented at Athletic Training Educators' Conference, Montgomery, TX. Retrieved January 1, 2011, from, http://www.nata.org/education/educational-programs/post-professionaleducation-programs

Johanson, M. (2004). Factors influencing professional master of physical therapy and doctor of physical therapy students' program selection. Journal of Physical Therapy Education, 18(2), 9-21.

Johanson, M. (2007). Factors influencing students' selection of physical therapist programs: Differences between men and women and racial/ethnic groups. Journal of Physical Therapy Education, 21(1), 22-32.

Johnston, T. C. (2010). Who and what influences choice of university? Student and university perceptions. American Journal of Business Education, 3(10), 15-22.

JRC-AT Tracks Entry-Level Athletic Training Grads. (2003, April). NATA News, 22-23.

Kanji, Z., Sunell, S., Boschma, G., \& Craig, B. J. (2010). Dental hygiene baccalaureate degree education in Canada: Motivating influences and experiences. Canadian Journal of Dental Hygiene, 44(4), 147-155.

Keskula, D. R., Sammarone, P.G., \& Perrin, D. H. (1995). Prediction of academic achievement in an NATA-approved graduate athletic training education program. Journal of Athletic Training, 30(1), 55-56.

Kippenbrock, T. (1990). School of nursing variables to male student college choice. Journal of Nursing Education, 29(3), 118-121.

Kindle, P. A., \& Colby, I. (2008). School selection preferences of public and private university MSW students: A retrospective study. Journal of Social Work Education, 44(3), 97-113.

Meadus, R. J. (2000). Men in nursing: Barriers to recruitment. Nursing Forum, 35(3), 12.

Miller, S. J. (1999). Approval of athletic training curriculums at colleges and universities. Journal of Athletic Training, 34(1), 62-63. 
National Athletic Trainers' Association. (2002, January). Standards and guidelines for post-certification graduate athletic training education programs. Retrieved January 1, 2011, from

http://www.nata.org/sites/default/files/standards-guidelines-postcertification-graduate.pdf

National Athletic Trainers' Association, (2011). Membership statistics. Retrieved June 1, 2011, from http://www.nata.org/membership

Perrin D. H. (2007). Athletic training: From physical education to allied health. Quest, 59 (1), 111-123.

Pitney, W. A., \& Parker, J. (2001). Qualitative inquiry in athletic training: principles, possibilities, and promises. Journal of Athletic Training, 36(2), 185-189.

Pitney, W. A., \& Parker, J. (2002). Qualitative research applications in athletic training. Journal of Athletic Training, 37(4), S168-S173.

Prentice, W. E. (2006). Arnheim's principles of athletic training: A competencybased approach. New York: McGraw-Hill.

Rasmussen-Wilbert, J. (2007). Perceived barriers to developing an entry-level master's degree program in athletic training (Doctoral dissertation, University of Memphis). Available from ProQuest Dissertations and Theses. (UMI No. 3263719)

Seegmiller, J. G. (2006). Perceptions of quality for graduate athletic training education. Journal of Athletic Training, 41(4), 415-421.

Turocy, P. S. (2002). Survey research in athletic training: The scientific method of development and implementation. Journal of Athletic Training, 37(4), S174-S179.

Wilcox, K. C., Weber, M., \& Andrew, D. L. (2005). Factors influencing minority students' choice of physical therapist education programs. Journal of Physical Therapy, 19(2), 8-14.

Winterstein, A. P. (2009). Education as a professional practice issue: Two ideas to improve athletic training. Athletic Training \& Sports Health Care, 1(2), 55-58.

Why pursue an accredited master's in AT? (2011, March). NATA News, 22-23. 


\section{Appendix A:}

\section{IRB Document}

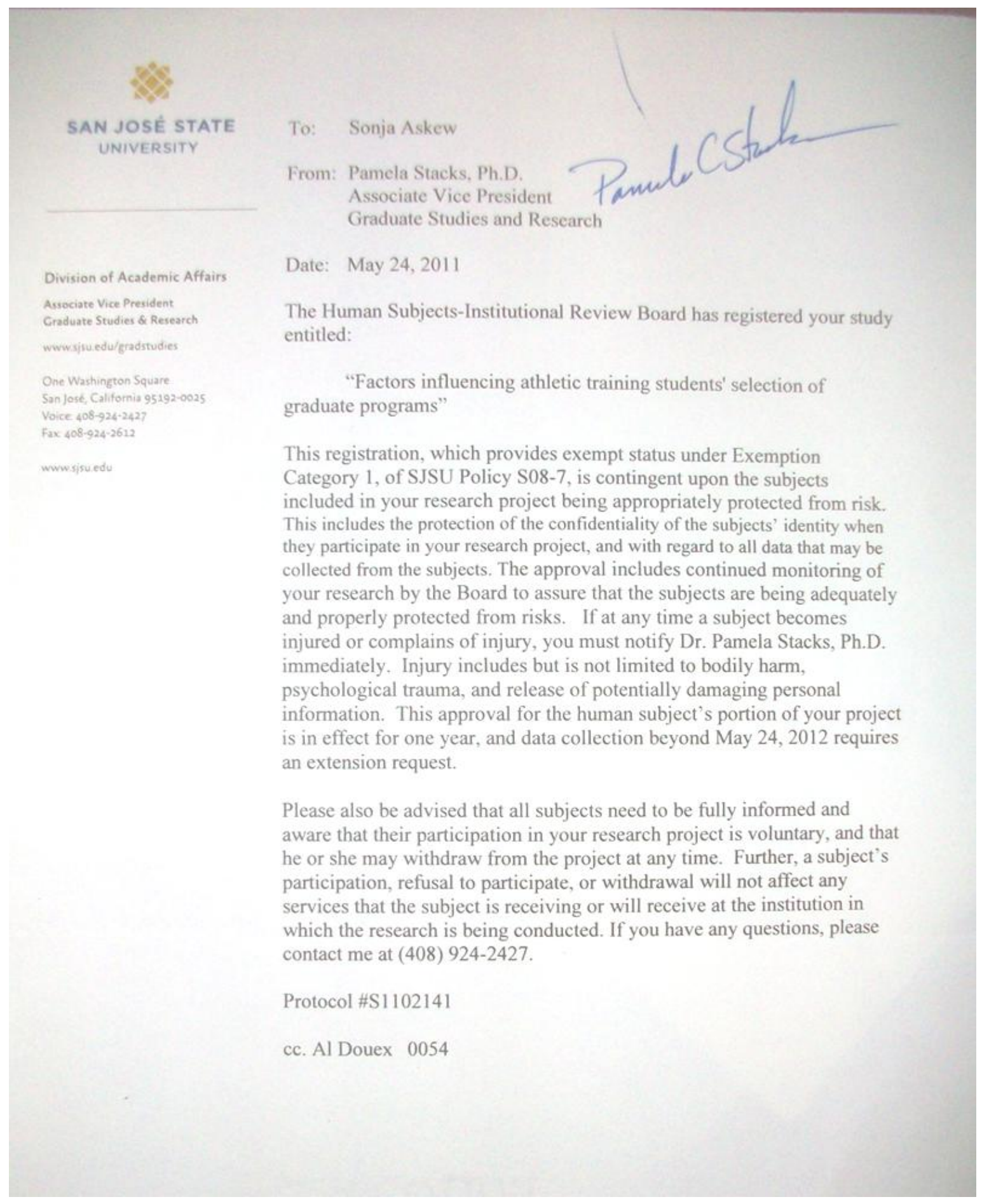




\section{Appendix B:}

\section{Letter to Program Directors/Head Athletic Trainers}

Dear [FirstName] [LastName],

Your participation in this research study would be greatly appreciated. Please, paste and forward the message below to all newly accepted students, currently enrolled students, and recent graduates:

Dear Graduate Students,

I am a graduate athletic training student at San José State University. I am investigating the factors that influence athletic training students' selection of a graduate program.

The survey features three sections: (1) Demographic Section; (2) Likert-Scale Section; and (3) Qualitative Section. Before beginning the survey, please read the letter of consent. The first part of the survey will consists of 10 demographic questions. Then you will be asked to rate the influence of 15 factors on your selection of a graduate program. The survey will conclude with 5 open-ended questions to further examine your decision. Overall, it may take 10 minutes to complete.

Please click the link below to partake in this research study.

[survey link]

Thank you for time and consideration,

Sonja Askew, ATC

San José State University

sonjaaskew@gmail.com

Please note: If you do not wish to receive further emails from us, please click the link below, and you will be automatically removed from our mailing list. [opt out link] 


\section{Appendix C:}

\section{Reminder Letter to Program Directors/Head Athletic Trainers}

Dear [FirstName] [LastName],

This is a reminder email kindly asking you to distribute or redistribute the survey to your students encouraging their participation in this IRB approved study. Please, paste and forward the following message to all newly accepted, recent graduates and currently enrolled graduate students:

Dear Graduate Students,

I am conducting a national study about the factors that influence students' selection of graduate programs. Your response would be greatly appreciated. This is a reminder email kindly asking you to complete the survey by Saturday, June 18, if you have not already done so.

Please click the link below to begin.

[survey link]

If you have completed the survey, please disregard this email and thank you very much for your contribution to my research.

Thanks again,

Sonja Askew, ATC

San José State University

sonjaaskew@gmail.com

Please note: If you do not wish to receive further emails from us, please click the link below, and you will be automatically removed from our mailing list. [opt out link] 


\section{Appendix D:}

\section{Letter to Graduate Students}

Dear Graduate Students,

I am a graduate athletic training student at San José State University investigating the factors that influence athletic training students' selection of graduate programs.

The survey [survey link] features three sections: (1) Demographic Section; (2) Likert-Scale Section; and (3) Qualitative Section. Before beginning the survey, please read the letter of consent. The first part of the survey will consists of demographic questions. Then you will be asked to rate the influence of different factors on your selection of a graduate program. The survey will conclude with 5 open-ended questions to further examine your decision. Overall, it may take 1015 minutes to complete.

Please click the link below to partake in this research study.

[survey link]

Thank you for your participation,

Sonja Askew, ATC

San José State University

sonjaaskew@gmail.com

Please note: If you do not wish to receive further emails from us, please click the link below, and you will be automatically removed from our mailing list. [opt out link] 


\section{Appendix E:}

\section{Reminder Letter to Graduate Students}

Dear Graduate Student,

I am conducting a national study about the factors that influence students' selection of graduate programs. Your response would be greatly appreciated. This is a reminder email kindly asking you to participate if you have not already done so.

Please click the link below to partake in this research study.

[survey link]

If you have completed the survey, please disregard this email and thank you very much for your contribution to my research.

Thanks again,

Sonja Askew, ATC

San José State University

sonjaaskew@gmail.com

Please note: If you do not wish to receive further emails from us, please click the link below, and you will be automatically removed from our mailing list. [opt out link] 


\section{Appendix F:}

\section{Sample Survey}

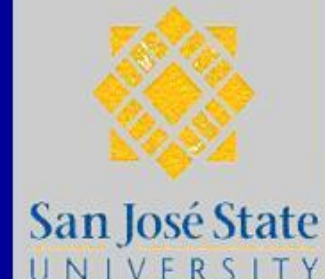

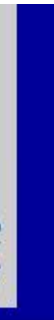

Dear Fellow Graduate Students \& Recent Graduates,

Your participation has been requested for an Institutional Review Board (IRB) approved research study investigating the factors that influenced your decision to attend the graduate program you selected. This study is being conducted nationally with all athletic trainers who have chosen to pursue a master's level educational program. The goal of this investigation is to provide a better understanding of the factors that influence students in their pursuits of higher education. By responding to the survey, you are positively contributing to scholarly research in the field of athletic training.

Your role in this research study will be to answer the questions as honestly as possible. The survey will take approximately 10 -15 minutes to complete.

In accordance with guidelines regarding research with human participants: (1) your participation is completely voluntary and there are no foreseeable risks or discomforts to you through participation; (2) nothing adverse will result from a decision not to participate; and (3) the results of this study may be published, but no identifying information will be included that could identify you. Moreover, by clicking the "NEXT" button below, you are giving informed consent to participate in this study. If you have already completed this survey, please click the "Exit this survey" button in the upper right corner.

I realize how valuable your time is and greatly appreciate your participation. Any questions or concerns you may have regarding the study may be addressed by the following:

Principal Investigator: Sonja Askew, ATC (909)276-1276 or sonjaaskew@gmail.com

Faculty Advisor: Dr. Payne (408) 924-3053 or greg.payne@sjsu.edu

Associate Vice President of Graduate Studies \& Research: Pamela Stacks (408)924-2488 or pamela.stacks@sjsu.edu

Sincerely,

Sonja Askew, ATC

\begin{tabular}{|l|l|}
\hline$\square$ & $10 \%$ \\
\hline
\end{tabular}




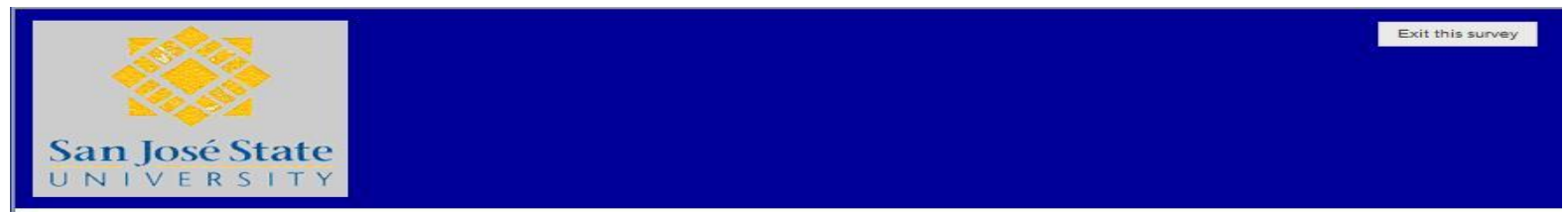

Please answer all of the following as truthfully as possible

1. Age

Less than 24 years old

Between 24 and 27 years old

Greater than 27 years old

\section{Ethnicity}

American Indian/Native American

Asian/Pacific-Islander

Black/African-American

Latino/Hispanic

White/Caucasian

Bi/Multi-racial

3. Gender

IC Male

Female
Single
Married
Divorced

4. Marital Status

5. Do you have any dependents?

Yes

No

6. State of Permanent Residence

Select a state.

7. I attend a graduate program...

in state

$\bigcirc$ out of state

8. Are you currently a member of NATA?

Yes

No

9. Indication your parent's highest education level.

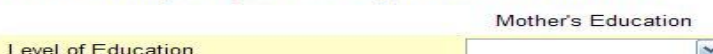

9. Indication your parent's highest education level.

Level of Education Mother's Education

Father's Education

10. Indicate the type of graduate program you attend.

My program is a

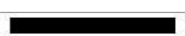

Prev Next 


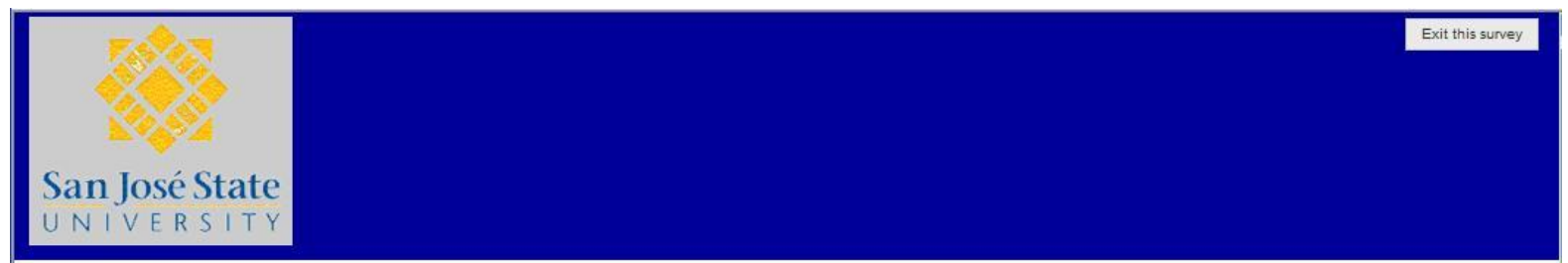

Please rate how the following factors influenced you in selecting a graduate program.

11. How did the following socioeconomic factors influence you?

Cost/Affordability
Amount of Financial Aid Available
Graduate Assistantship Offered
Teaching/Research Assistantship
Offered
Family
Approved Clinical Instructor
ATEP Program Director
Alumni

Not Important
0
0
0
0
0




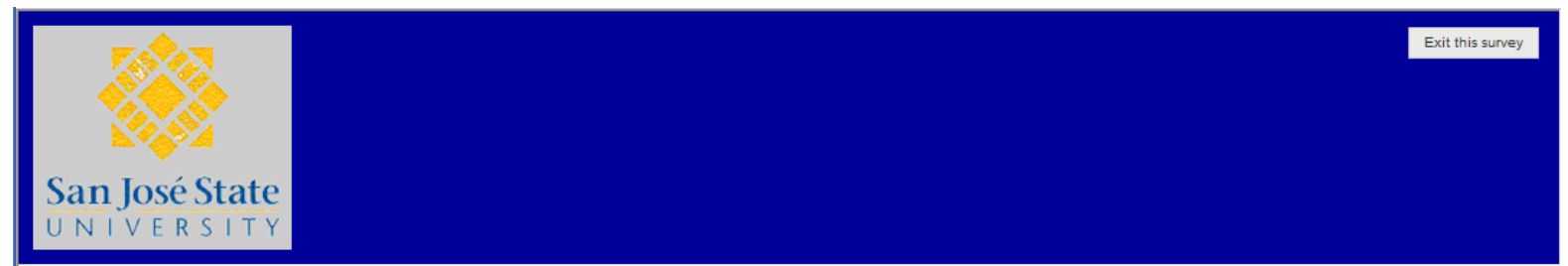

Please rate how the following factors influenced you in selecting a graduate program.

12. How did the following geographic factors influence you?

Location of Program
Distance from Home
Size of City/Town
Cost of Living
Crime Rate
Weather Conditions

Weather Conditions 
San José State

UNIVERSITY

Please rate how the following factors influenced you in selecting a graduate program.

13. How did the following diversity factors influence you?

Faculty Similar in Ethnicity
Faculty of Same Gender
Campus Activities Related to
Ethnicity/Culture
Diversity of Student Body
Students Similar in
Ethnicity/Gender
Campus/Student Life

Campus/Student Life

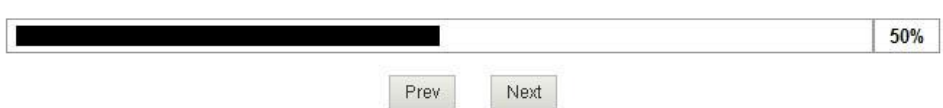


San José State

UNIVERSITY

Please rate how the following factors influenced you in selecting a graduate program.

14. How did the following program \& faculty factors influence you?

Status of Accreditation
Degree Conferred
Admission Requirements
Student/Faculty Ratio or Class
Size
Clength of Program
Prestige of Faculty
Prestige of Program

$\begin{array}{cc}\text { Not Important } & \text { N/A } \\ 0 & 0 \\ 0 & 0 \\ 0 & 0 \\ 0 & 0 \\ 0 & 0 \\ 0 & 0 \\ 0 & 0 \\ 0 & 0\end{array}$

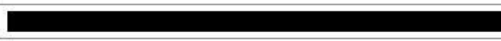




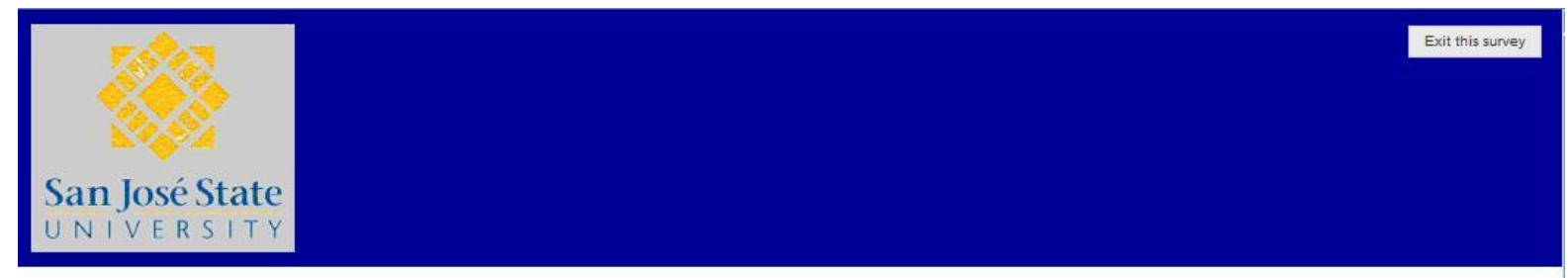

Please rate how the following factors influenced you in selecting a graduate program.

15. How did the following college/university factors influence you?

\begin{tabular}{|c|c|c|c|c|}
\hline & Very Important & Moderately Important & Not Important & N/A \\
\hline $\begin{array}{l}\text { Prestige (general univ. reputation } \\
\text { or ranking) }\end{array}$ & & & & \\
\hline $\begin{array}{l}\text { Type of Institution (Carnegie } \\
\text { classification) }\end{array}$ & & & & \\
\hline Size of Enrollment & O & O & O & \\
\hline Marketability of Degree & O & O & O & \\
\hline Prestige of Institution's Athletics & O & O & O & \\
\hline Perceived Quality of Education & O & 0 & 0 & \\
\hline Attractiveness/Appearance & 0 & 0 & 0 & $D$ \\
\hline Campus Facilities & $\mathrm{O}$ & O & 0 & \\
\hline
\end{tabular}

Prev Next 


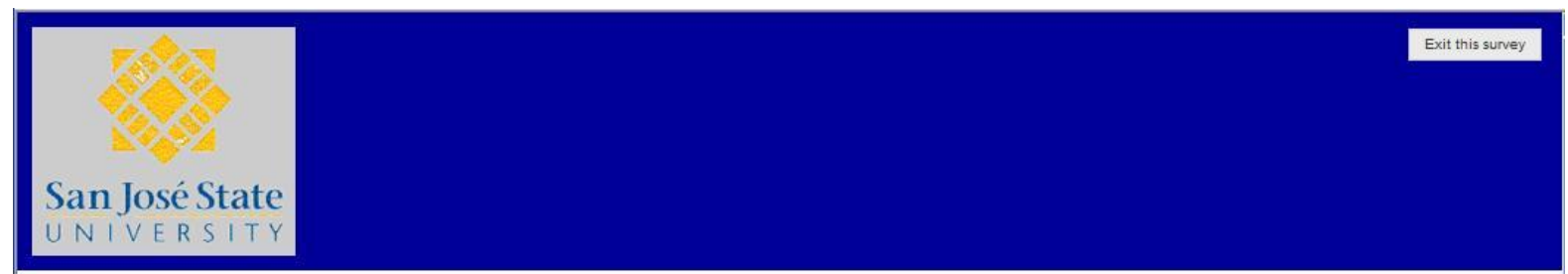

Please rate how the following factors influenced you in selecting a graduate program.

16. How did the following motivational factors influence you?

Self-Improvement
Aspiration
Recognition
Ability to Contribute to Profession
Desire for Knowledge

Not Important

N/A

O

O

O

$\bigcirc$

○

17. Overall, what was the most influential factor?

Select one factor. 


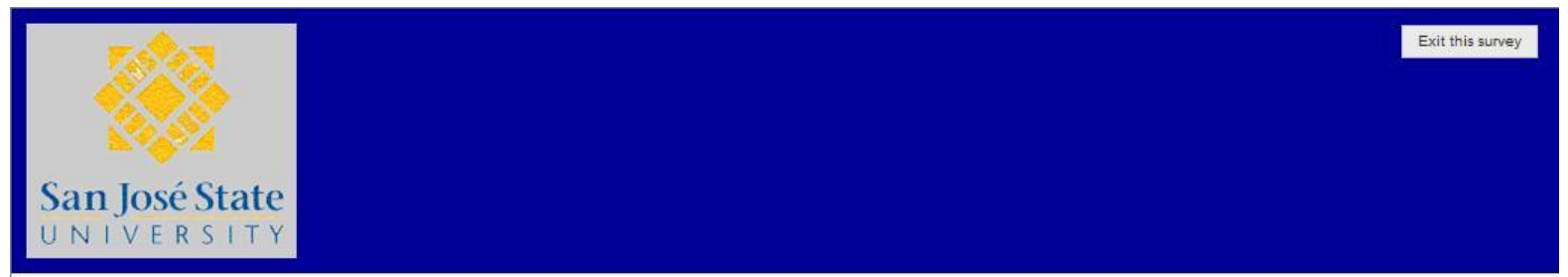

This is the last page of the survey. These questions are optional. Feel free to write a brief response, but please write in complete sentences. 18. Who was the most influential person in making your decision?

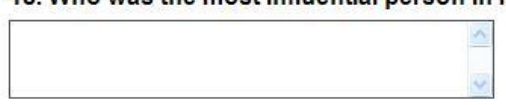

19. In what ways did your undergraduate ATEP aid you in your pursuit of an advanced degree?

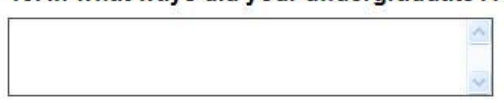

20. What information or knowledge was passed on to you pertaining to continuing your education and by whom?

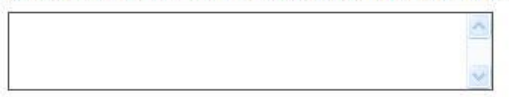

21. What is your career goal? (e.g. High School- Head AT)

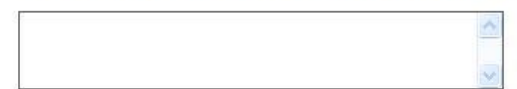

22. Upon finishing your master's degree, will you pursue a doctoral degree? Why or why not?
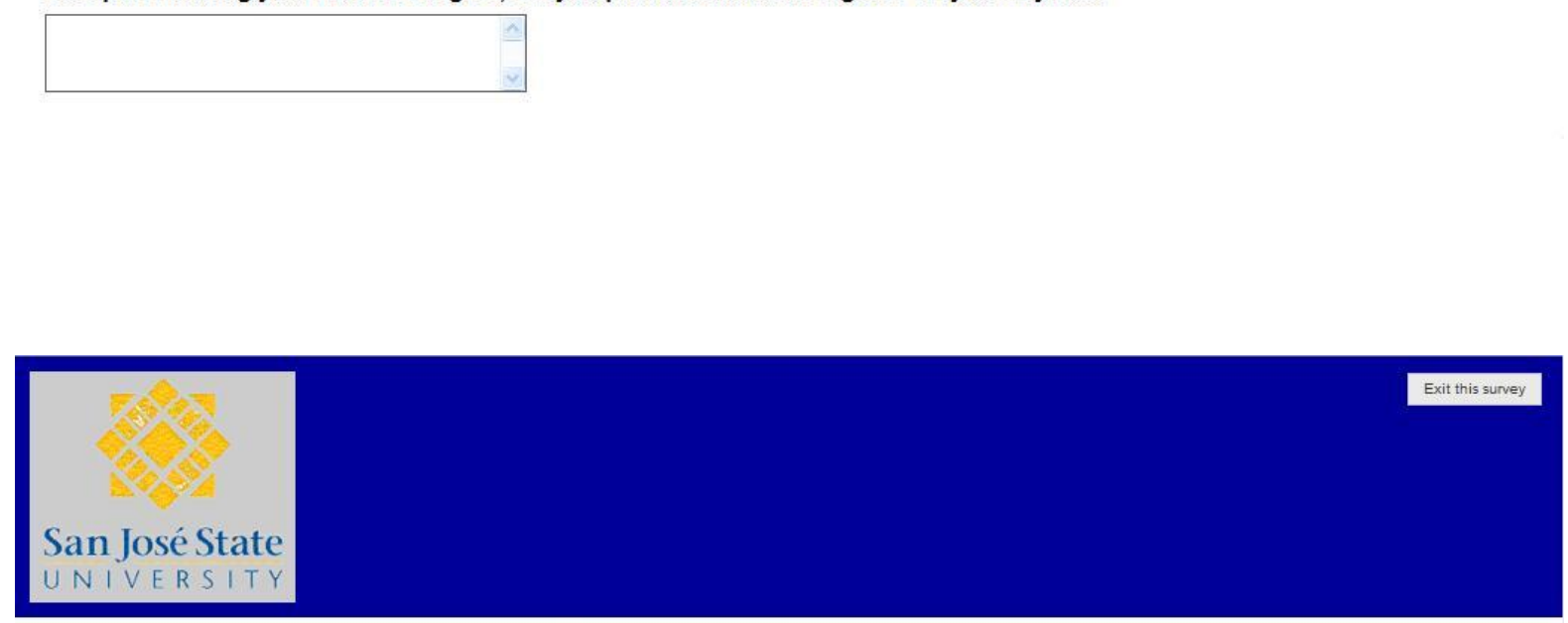

Thank you for participating in this survey. I greatly appreciate your time and feedback.

Prev Done 